Article

\title{
Functional Characterization of Allatostatin C (PISCF/AST) and Juvenile Hormone Acid O-Methyltransferase in Dendroctonus armandi
}

\author{
Yaya Sun ${ }^{1,2}$, Danyang Fu ${ }^{2}$, Bin Liu ${ }^{2}$, Linjun Wang ${ }^{2}$ and Hui Chen ${ }^{1, *}$ \\ 1 State Key Laboratory for Conservation and Utilization of Subtropical Agro-Bioresources, College of Forestry \\ and Landscape Architecture, South China Agricultural University, Guangzhou 510642, China; \\ sunyaya@nwafu.edu.cn \\ 2 College of Forestry, Northwest A\&F University, No. 3 Taicheng Road, Yangling, Xianyang 712100, China; \\ fudanyang@nwsuaf.edu.cn (D.F.); liubin95@nwsuaf.edu.cn (B.L.); 2020060253@nwafu.edu.cn (L.W.) \\ * Correspondence: chenhui@scau.edu.cn; Tel.: +86-02085280256
}

check for updates

Citation: Sun, Y.; Fu, D.; Liu, B.;

Wang, L.; Chen, H. Functional Characterization of Allatostatin C (PISCF/AST) and Juvenile Hormone Acid O-Methyltransferase in Dendroctonus armandi. Int. J. Mol. Sci. 2022, 23, 2749. https://doi.org/ $10.3390 /$ ijms 23052749

Academic Editor: Manickam Sugumaran

Received: 24 January 2022 Accepted: 27 February 2022 Published: 2 March 2022

Publisher's Note: MDPI stays neutral with regard to jurisdictional claims in published maps and institutional affiliations.

Copyright: (C) 2022 by the authors. Licensee MDPI, Basel, Switzerland. This article is an open access article distributed under the terms and conditions of the Creative Commons Attribution (CC BY) license (https:// creativecommons.org/licenses/by/ $4.0 /)$.

\begin{abstract}
Allatostatin C (PISCF/AST) is a neuropeptide gene that affects juvenile hormone (JH) synthesis in the corpora allata. Juvenile hormone acid O-methyltransferase (JHAMT) is a key gene in the JH biosynthetic pathway. In this study, two genes encoding DaAST and DaJHAMT were cloned. Both DaAST and DaJHAMT were expressed in the larvae, pupae and adults of Chinese white pine beetle (Dendroctonus armandi), and highly expressed in the head and the gut. The expression of the two genes was induced by $\mathrm{JH}$ analog (JHA) methoprene and the functions of the two genes were then investigated by RNAi. Considering the role of hormones in metamorphosis, JHA significantly induced DaAST and DaJHAMT in the larval stage. DaAST knockdown in larvae, pupae and adults significantly increased the DaJHAMT mRNA levels. Moreover, knockdown of DaAST instead of $D a J H A M T$ increased pupae mortality and the abnormal rate of emergence morphology and reduced emergence rates. However, knockdown of DaJHAMT instead of DaAST significantly reduced frontalin biosynthesis in adult males. The results showed that DaAST acts as an allatostatin and inhibits JH biosynthesis, and that JHAMT is a key regulatory enzyme for $\mathrm{JH}$ synthesis in the D. armandi.
\end{abstract}

Keywords: Chinese white pine beetle; juvenile hormone (JH); development; frontalin; RNAi

\section{Introduction}

Insect juvenile hormone $(\mathrm{JH})$, a multifunctional hormone secreted from the corpora allata (CA), plays a role in multiple physiological events including diapause, pheromone production, polyphenisms, growth, molting, metamorphosis and reproduction [1-7]. The JH biosynthetic pathway was conventionally divided into two phases: early steps (the upstream mevalonate pathway, MVAP) and late steps (the isoprene branch pathway, JHbranch) $[8,9]$. The early steps follow the mevalonic acid pathway to form farnesyl pyrophosphate (FPP) and involve several enzymes. Initially, three units of Acetyl-CoA are condensed into mevalonate through three sequential steps involving acetoacetyl-CoA thiolase $(A A C T)$, 3-hydroxy-3-methylglutaryl-CoA synthase (HMG-S) and 3-Hydroxy-3methylglutaryl-CoA reductase $(H M G-R)$. Then, mevalonate is converted to isopentenyl diphosphate (IPP) through three enzymatic reactions catalyzed by mevalonate kinase $(M K)$, phosphomevalonate kinase $(P M K)$, and mevalonate diphosphate decarboxylase $(M P D C)$ [10]. Isopentenyl diphosphate isomerase (IPPI) catalyzes the conversion of isopentenyl pyrophosphate (IPP) to dimethylallyl pyrophosphate (DMAPP); subsequently, IPP and DMAPP were condensed head-to-tail manner to produce geranyl diphosphate (GPP); this head-to-tail condensation can be repeated by the further reaction of GPP with IPP, yielding the JH precursor farnesyl diphosphate (FPP) [11]. The expressions of eight enzymes of the mevalonate pathway have been previously examined in Dendroctonus armandi $[12,13]$. 
During the late steps proceeding from farnesyl diphosphate to JH, FPP is transformed sequentially to farnesol, farnesal, farnesoic acid, methyl farneosate and JH [10,14-16]. The juvenile hormone acid O-methyltransferase (JHAMT) is a key regulatory enzyme in the isoprene branch pathway that is essential for insect growth and reproduction [17,18]. For example, silencing the TCJHAMT gene in the larval stage of Tribolium castaneum resulted in premature larva-pupa metamorphosis [19]. In particular, the genes encoding enzymes for the mevalonate pathway and the last two steps of the $\mathrm{JH}$ branch pathway (farnesoic acid (FA) epoxidase and JHAMT) have been identified in multiple species [10,17-24].

Different factors are involved in the regulation of JH synthesis [14]. These include allatoregulatory neuropeptides, biogenic amines [25,26], nutritional signals [27] and nuclear receptors [28]. In insects, one of the largest groups of neuropeptides is the group of allatostatins (ASTs). ASTs have been identified in beetles, cockroaches, crickets, flies, moths, stick insects, and termites [29-37]. ASTs were first divided into three distinct families: Type A [37], Type B [33] and Type C allatostatin [29,38,39]. However, because the classification of families did not address either the biological properties of these peptides or the structure of the amino acid chains of these peptides, Coast \& Schooley (2011) systematized the nomenclature of these neuropeptides [40]. They proposed that A Type allatostatin should be named FGL/AST because of the presence of an FGL sequence at the C-terminal end, Type B should be named MIP/AST because of the myoinhibitory properties of these peptides on the visceral muscles, and Type $C$ should be named PISCF/AST, because there is an uncommon PISCF-OH sequence at the C-terminal end [40]. In coleopteran species, in vitro studies showed that the Tribolium castaneum $A S-B 3$ peptide inhibited CA activity, while TcAS-C inhibited or stimulated JH biosynthesis [41]. Furthermore, the injection of double-stranded RNAs (dsRNAs) targeting TcAS-C and TcAS-B into young T. castaneum pupae prolonged pupae duration and resulted in the production of approximately $50 \%$ of deformed adults. The other 50\% were intact in shape [42]. Moreover, in Leptinotarsa decemlineata, the mRNA levels of LdJHAMT were significantly increased and the larval growth and delayed development of $L$. decemlineata were significantly affected after continuous ingestion of $d s L d A S-C$ [43]. However, the in vivo allophilic activity of AST-C peptides in other Discoptera species remains unproven.

RNA interference (RNAi) is the process by which exogenous double-stranded RNA (dsRNA) silences complementary endogenous messenger RNA (mRNA) [44]. Since being discovered in Caenorhabditis elegans [45], RNAi first achieved successful insect action in Drosophila melanogaster [46]. Due to its high specificity, RNAi has great potential for pest control [47-49]. It has rapidly developed into a widely used tool in a variety of insects, including Hymenoptera [50,51], Diptera [52,53], Coleoptera [54,55] and Lepidoptera [56-58]. There are two ways to deliver dsRNA to insect target tissues: injection and ingestion $[59,60]$. Of these two methods, the RNAi feeding program has several advantages over the injection method, the most important of which is that it is more convenient and labor-saving. It has been reported that transgenic plants that produce dsRNA targeting selected insect genes have shown inhibitory effects on cotton bollworm [61] and western corn rootworm [47]. Their expression induced by $\mathrm{JH}$ analog (JHA) was analyzed in different tissues at different developmental stages through a series of RNAi experiments.

In this study, we used RNA interference to characterize the functions of the two genes DaAST and DaJHAMT in the Chinese white pine beetle (Dendroctonus armandi), and analyzed the expression levels of JH biosynthesis genes after knocking down DaAST and DaJHAMT; their effects on development were also investigated. More broadly, the injection of bacterially expressed dsRNA may be suitable for large-scale optimized gene screening of RNAi-ingestible plants to provide a theoretical basis for understanding the molecular mechanisms of allatostatin C (PISCF/AST) and juvenile hormone acid O-methyltransferase in Chinese white pine beetle. 


\section{Results}

\subsection{Identification of DaAST and DaJHAMT Genes}

$D a A S T$ was identified in D. armandi and the full-length sequences shared high identity (64-69\%) with Dendroctonus ponderosae, T. castaneum and L. decemlineata (Table 1). The deduced amino acid sequence of DaJHAMT had high identity (53\%) to the JHAMT of D. ponderosae. DaJHAMT also showed a relatively high amino acid identity $(36.8 \%$ and $36.5 \%$ ) to the JHAMT predicted from the genomes of Nicrophorus vespilloides and Aethina tumida. These sequences of $D$. armandi had the highest identity to $D$. ponderosae according to a neighbor-joining method analysis of the putative full-length amino acid sequences (Figure 1).

Table 1. Amino acid identity of putative allatostatin $(D a A S T)$ and juvenile hormone acid Omethyltransferase (DaJHAMT) with related sequences in other insect species.

\begin{tabular}{|c|c|c|c|c|}
\hline \multirow{2}{*}{ Genes } & \multicolumn{3}{|c|}{ BLAST Matches in Genbank } & \multirow{2}{*}{$\frac{\text { Identity }^{1}}{\text { BlastP }}$} \\
\hline & Species & Gene & Accession No. & \\
\hline \multirow{3}{*}{ DaAST } & Dendroctonus ponderosae & AST & XP_019760338.1 & $69 \%$ \\
\hline & Tribolium castaneum & $A S T$ & NP_001137205.1 & $67 \%$ \\
\hline & Leptinotarsa decemlineata & AST & AIW62334.1 & $64 \%$ \\
\hline \multirow{3}{*}{ DaJHAMT } & Dendroctonus ponderosae & JHAMT & XP_019760146.1 & $53 \%$ \\
\hline & Nicrophorus vespilloides & $J H A M T$ & XP_017772157.1 & $36.8 \%$ \\
\hline & Aethina tumida & JHAMT & XP_019876726.1 & $36.5 \%$ \\
\hline
\end{tabular}

${ }^{1}$ As predicted by BLAST (www.ncbi.nlm.nih.gov, accessed on 12 February 2021) [62].
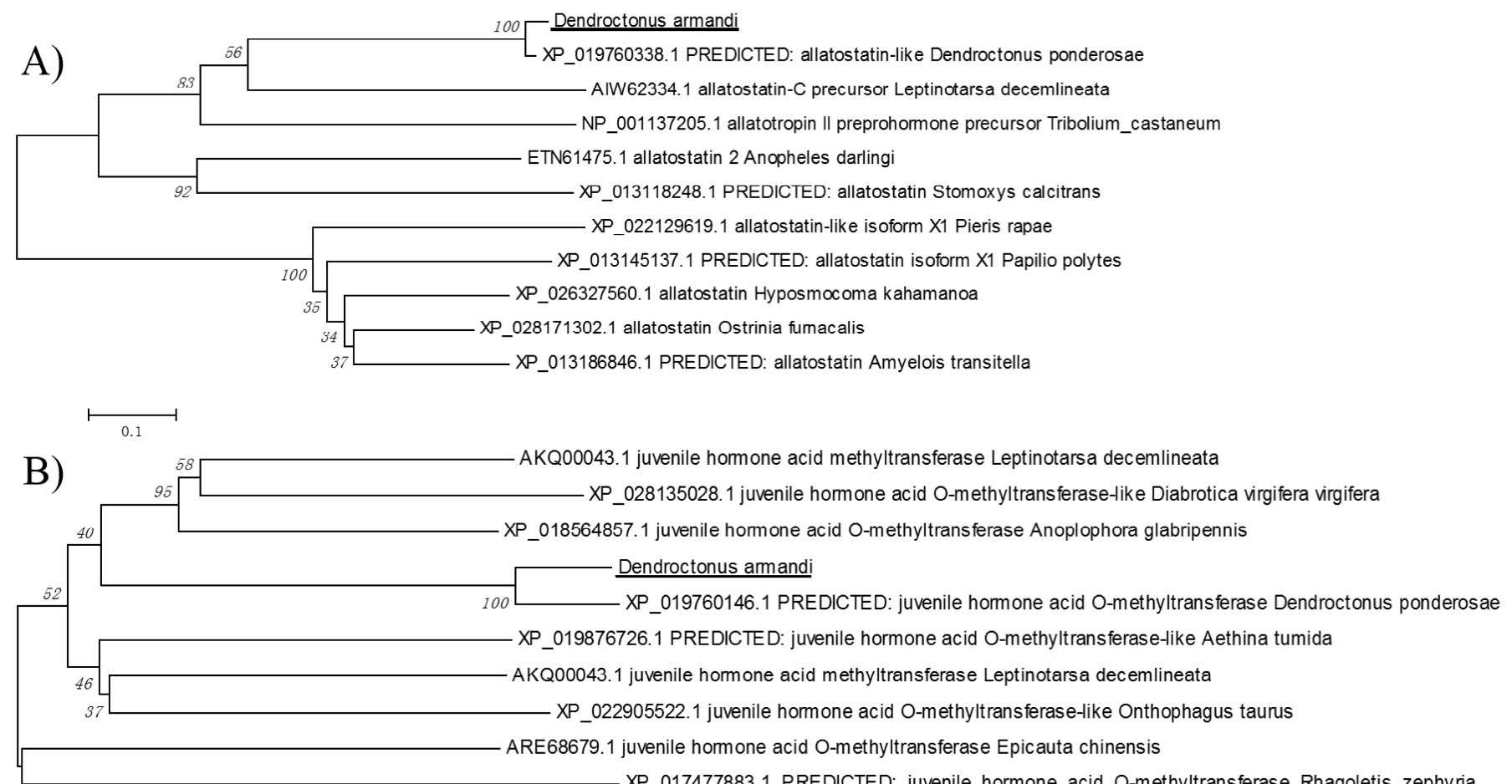

XP_017477883.1_PREDICTED:_juvenile_hormone_acid_O-methyltransferase_Rhagoletis_zephyria

Figure 1. Phylogenetic tree of allatostatin (DaAST) and juvenile hormone acid O-methyltransferase (DaJHAMT) from Dendroctonus armandi. (A) Phylogenetic analysis of DaAST; (B) Phylogenetic analysis of DaJHAMT. The two sequences from D. armandi are marked in black. The phylogenetic trees were constructed with MEGA7.0 using the neighbor-joining method. Values indicated at the nodes are bootstrap values based on 1000 replicates. 


\subsection{Physicochemical Properties and Bioinformatic Analysis}

The full-length open reading frames (ORFs) of DaAST and DaJHAMT were $345 \mathrm{bp}$ (DaAST) and $848 \mathrm{bp}$ (DaJHAMT) encoding 114 (DaAST) and 275 (DaJHAMT) amino acids. Respectively, the predicted molecular masses were $13.28 \mathrm{kDa}(D a A S T)$ and $15.11 \mathrm{kDa}$ (DaJHAMT), and the isoelectric point ranged from 8.66 (DaAST) to 9.04 (DaJHAMT); the predicted subcellular location of DaAST and DaJHAMT by Target P1.1 program suggests cytoplasmic location (Table 2).

Table 2. Physicochemical properties and cellular localization of DaAST and DaJHAMT of D. armandi.

\begin{tabular}{|c|c|c|c|c|c|c|}
\hline Gene Name & $\begin{array}{c}\text { Accession } \\
\text { No. }\end{array}$ & $\begin{array}{l}\text { Full Length } \\
\text { (bp) })^{1}\end{array}$ & $\begin{array}{l}\text { ORF Size } \\
(\mathrm{aa} / \mathrm{bp})^{1}\end{array}$ & $\operatorname{Mw}(\mathrm{kDa})^{1}$ & I.P. ${ }^{1}$ & Signal Peptide Prediction ${ }^{2}$ \\
\hline DaAST & MW645339 & 471 & $114 / 345$ & 13.28 & 8.66 & SP 0.766 mTP 0.043 other 0.194 \\
\hline DaJHAMT & MW645341 & 1137 & $275 / 828$ & 15.11 & 9.04 & SP 0.069 mTP 0.062 other 0.932 \\
\hline
\end{tabular}

${ }^{1}$ As predicted by ProtParam [63]. ${ }^{2}$ As predicted by Target P 1.1 [64]. I.P.: isoelectric point; Mw: molecular weight; ORF: open reading frame; SP: secretory pathway signal peptide; mTP: mitochondrial targeting peptide.

According to the expected cleavages from insect neuropeptide convertase, the archetypal AST-C peptides in hymenopteran, anopluran, hemipteran and zooplankton species have the primary sequence SYWKQCAFNAVSCF amide [65]. The PISCF/AST sequences of L. decemlineata, D. ponderosae and D. armandi are RFRA (L) CYFNPVSCF (Figure 2A) [66]. It is known that the putative SAM-binding motif (motif I) is well conserved in all five methyl transferases, hh (D/E) hGXGXG (where h represents a hydrophobic residue). The motif I of DaJHAMT (ALDLGCGEG) was nearly identical to that of DponJHAMT (AIDLGCGEG) (Figure 2B). The DaAST and DaJHAMT sequences are structurally similar to those of $D$. melanogaster and Tenebrio molitor, further confirming that they are homologues of AST and JHAMT.

\subsection{DaAST and DaJHAMT Transcript Levels in D. armandi at Different Life Stages and in Different Tissues}

The transcript levels of $D a A S T$ throughout the developmental stages were determined using qRT-PCR. Relative to larvae, one-way ANOVA showed statistically significant differences in transcript expression levels among different development stages $(F=6.128$, $\mathrm{df}=14, p<0.0001$ ) (Figure 3). The expression of DaAST showed a downward trend in larvae, beginning with small larvae and reaching the lowest value in mature larvae. The expression then decreased in the pupae and reached a peak on the second day of the pupal stage, then dropped to a second trough that appeared at the teneral stage. In adults, the expression reached a maximum in emergent females and decreased to some extent, beginning in feeding females. The expression levels in females were higher than those in males (Figure 3A). 


\section{A)}

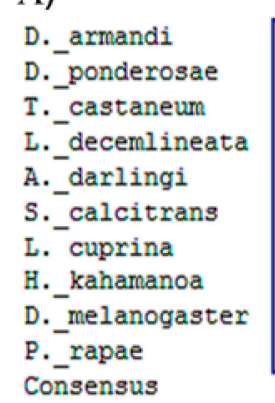

..MQYELEQ $\ldots \ldots$ VISRVFFAIIMMSIV . NAR PHYQENTQQG. LSADQES.TLNNVL ...ISGLRE $\ldots \ldots \ldots$ WQLE

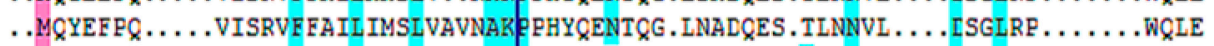
$\ldots$ MAAQLPR $\ldots \ldots$ YLTKTLE IFLIATLVVANAR ENHFGDAS $\ldots$ QVVGEPADGNNLL $\ldots$ ISRIKR $\ldots \ldots \ldots \ldots$ W

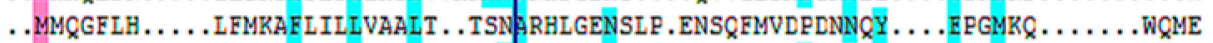
..MTAPVTL ...... SRQIL FAMALLCVVRCQGTSR EQNAIDNQ ... DLPEINPNELRKLYTN. YNSYVSN ... QLLNYGLD . . MMNISMG . . . . . FALLVEATIALSSESMTDAR EQNTPDSNQSVDPIDTDIEDLRSIY . . . YIVPVQQ . . NLYPNLPID . MISICK ........SVILFTIFMIITIVYIEAR EQNALDSNQALDTVETDVDEMQNSY... YILPLQQPQNIYPSIPLE MRTSATYSS.... MLMVGTL ALILCAVVAA PMDA EDECTQNGMEAHSNDINDVDYSGSMDA INIAALRKLLLQLDADDRL ..MMRFVQ.......ILLCYGLILTLFFALSEAR SGAETGPDSDGLDGQDAEDVRGAYGGGYIMPAQA ... IYPNIPMD MNGFSIHNNSIALLFAILTFFLMTSLVLTAPLDSEDEPGENTLIGRP . MMGEADMT . .WDAINTDALRKMLMQLDAEERL

D._armandi

D. ponderosae

T._castaneum

L. decemlineata

A. darlingi

s. calcitrans

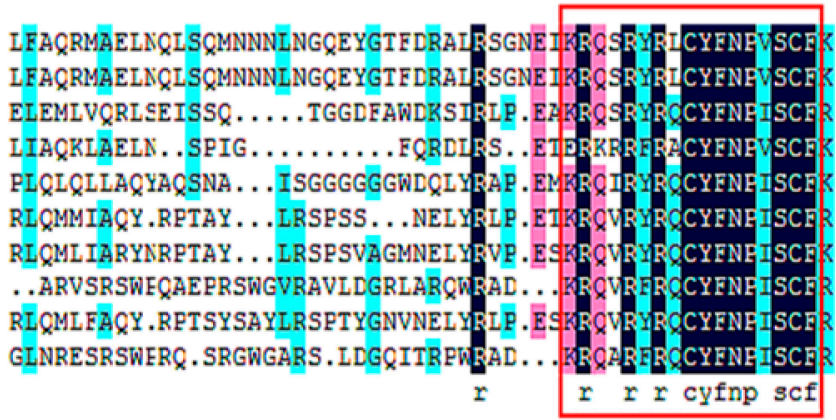

L. cuprina

H._kahamanoa

D. melanogaster

P._rapae

Consensus

B)

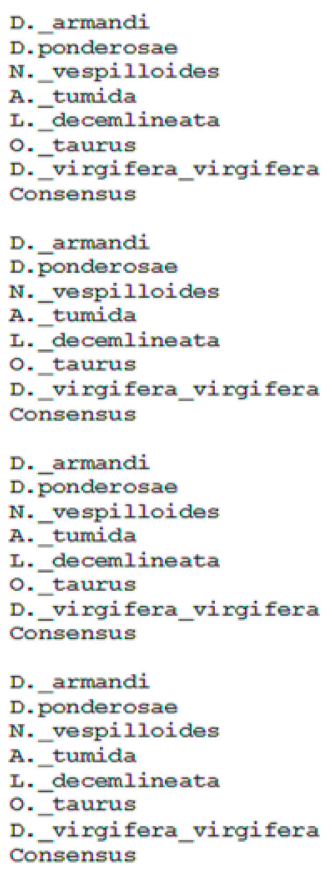

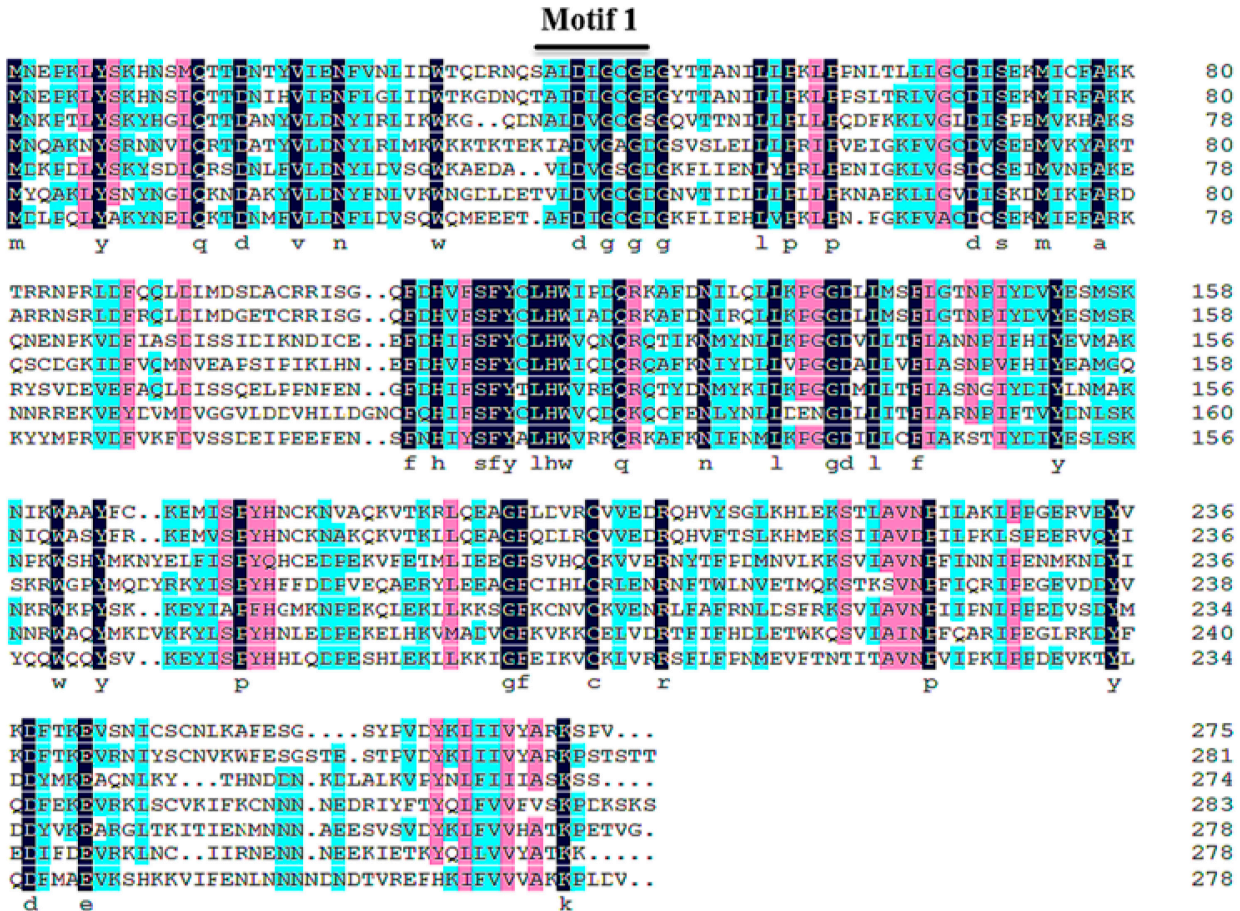

Figure 2. Structure of DaAST and DaJHAMT in D. armandi. (A) Alignment of putative DaAST sequence in beetle species and their consensus sequences with $D$. armandi sequences identified in this study. The blue color indicates similarities in the amino acid sequence. Blue frames: signal peptides at the N-termini; black: endopeptidase cleavage sites; red frames: other deduced MIP isoforms. (B) Alignment of DaJHAMT sequences. The conserved motif I of all SAM-dependent methyl transferases is marked with a bar above the sequences. 

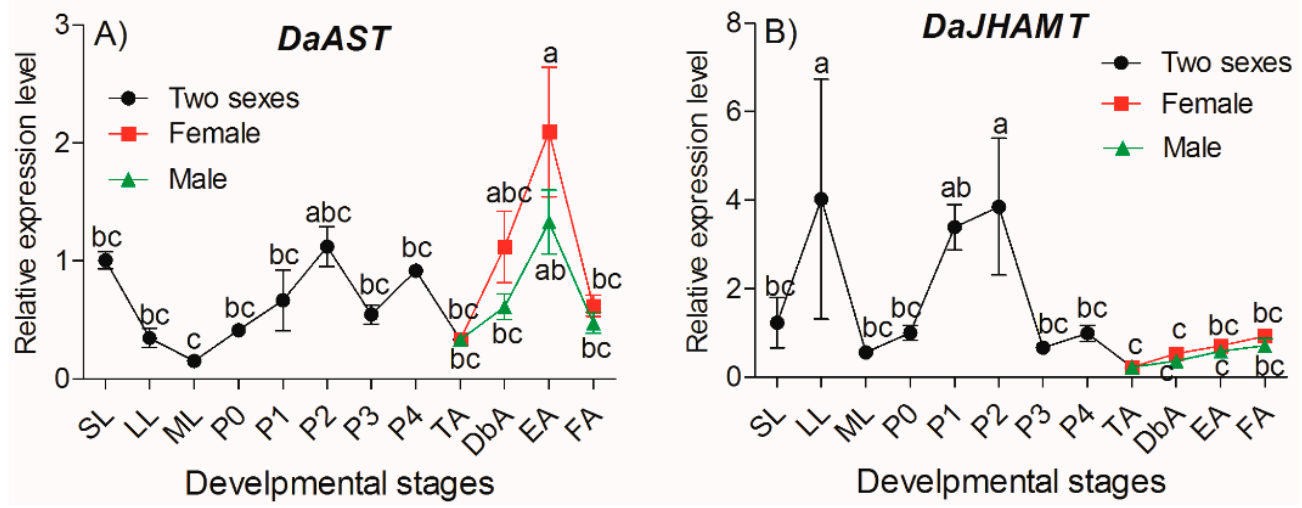

Figure 3. Relative expression of DaAST and DaJHAMT genes in different stages of $D$. armandi. (A) DaAST; (B) DaJHAMT. Small larvae (SL), large larva (LL), mature larvae (ML), pupae (P0, P1, P2, P3, P4), teneral adults (TA), dark brown adults (DbA), emergent adults (EA) and feeding adults (FA) of $D$. armandi. The results represent the mean $\pm \mathrm{SE}$ of three independent experiments. All templates were normalized with CYP4G55 and $\beta$-actin. The $2^{-\Delta \Delta C t}$ and SE values were used for plotting and the significant differences between different stages of DaAST or DaJHAMT were marked with letters (one-way ANOVA, $p<0.05$, with Tukey's test of multiple comparisons).

The transcript levels of DaJHAMT throughout the developmental stages were determined using qRT-PCR. Relative to larvae, a one-way ANOVA showed statistically significant differences in transcript expression levels among different development stages $(F=2.402, \mathrm{df}=14, p=0.022$ ) (Figure 3B). In larvae, the expression of DaJHAMT first increased and then decreased. From pupae to the teneral stage, the expression patterns of DaJHAMT were similar to those of AST. In adults, the expression levels of DaJHAMT remained constant from the teneral stage to the feeding adult stage but were lower than the levels in pupae (Figure 3B).

The tissue distribution of DaAST and DaJHAMT transcripts in various tissues from three developmental stages (larva, pupa, adult) were investigated by real-time RT-PCR analysis.

For $D a A S T$, at the larva stage, statistically significant differences were not found among different tissues of DaAST (Figure 4A); in the pupa, the expression of DaAST in the head reaches the highest level $(F=11.562, \mathrm{df}=3, p=0.003)$; During the period of adult emergence, the highest expression level of DaAST was observed in female and male anterior midguts (female: $F=7.038, \mathrm{df}=6, p=0.001$; male: $F=19.926, \mathrm{df}=6, p<0.0001$ ) (Figure 4C).

For DaJHAMT, quantitative RT-PCR (qRT-PCR) analysis of DaJHAMT showed that statistically significant differences were found among different tissues in all developmental stages. DaJHAMT was highly expressed in larval and pupal heads, and the highest expression was found in the larval and pupal guts (larva: $F=4.386, \mathrm{df}=3, p=0.042$; pupa: $F=15.022, \mathrm{df}=3, p=0.001$ ) (Figure $4 \mathrm{~B}$ ). During the period of adult emergence, statistically significant differences were not found among the different tissues of females $(F=1.703$, $\mathrm{df}=6, p=0.193)$. Meanwhile, the highest expression level of DaJHAMT was observed in male Malpighian tubules $(F=15.369, \mathrm{df}=6, p<0.0001)$; the anterior midgut and hindgut had higher expression volumes than the other tissues (Figure 4D). 

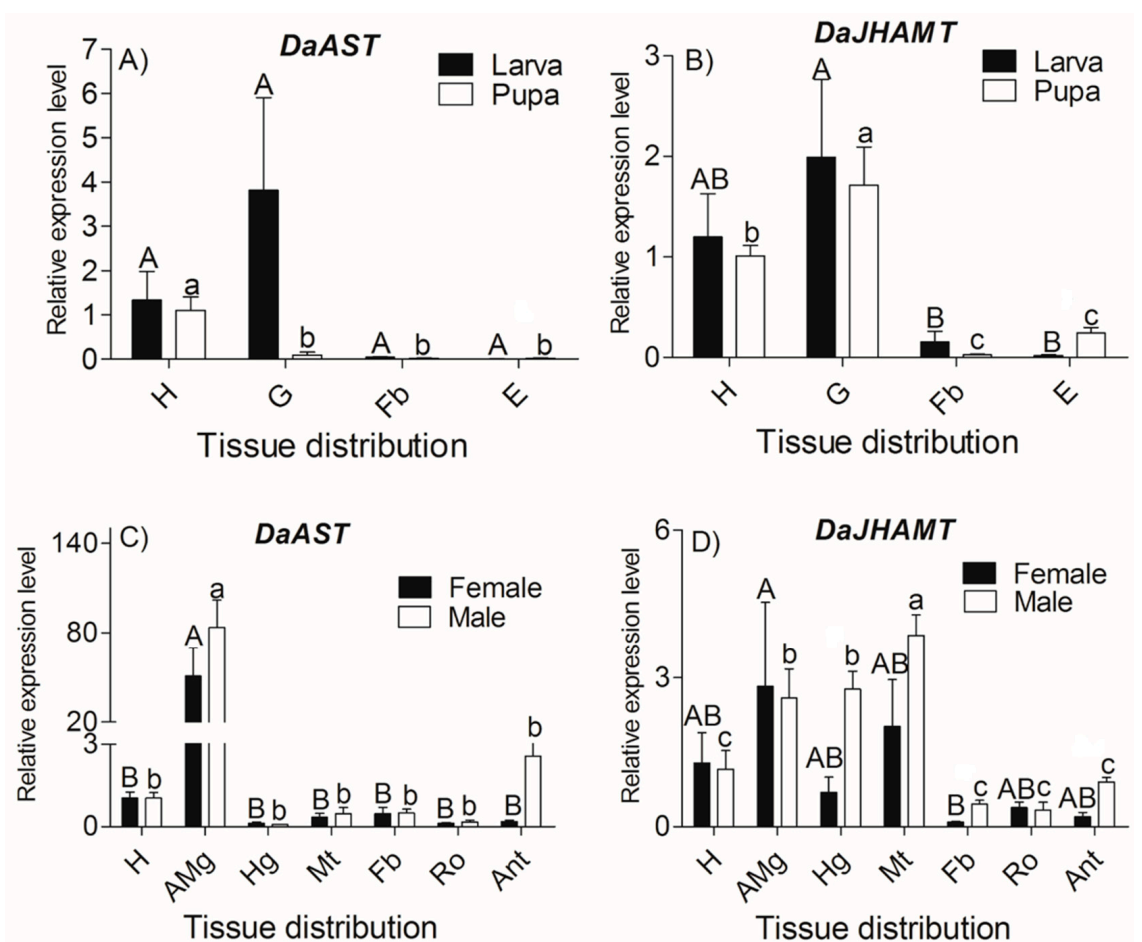

Figure 4. Relative expression of DaAST and DaJHAMT genes (mean $\pm \mathrm{SE}$ ) in different tissues of larvae, pupae and emergent adults. (A) DaAST of larvae and pupae; (B) DaJHAMT of larvae and pupae; (C) DaAST of emergent adults and (D) DaJHAMT of emergent adults. The tissues included the head $(\mathrm{H})$, anterior midgut $(\mathrm{AMg})$, hindgut $(\mathrm{Hg})$, Malpighian tubule $(\mathrm{Mt})$, fat body $(\mathrm{Fb})$, reproductive organ (Ro: testes of males and ovaries of females), antennae (Ant), gut (G) and epidermis (E) of $D$. armandi. The results represent the means \pm SE of three independent experiments. In both graphs, transcript levels are represented as relative expression to the head $(\mathrm{H})$ of males and females. All templates were normalized with CYP4G55 and $\beta$-actin. The $2^{-\Delta \Delta C t}$ and SE values were used for plotting. Uppercase letters mark significant differences in females or larvae, while lowercase letters mark males or pupae (one-way ANOVA, $p<0.05$, with Tukey's test of multiple comparisons).

\subsection{Effects of JHA Injection on Transcript Levels of DaAST and DaJHAMT}

To reveal the molecular mechanism of the influence of JHA on the expression of $D a A S T$ and DaJHAMT, the relative expression profiles of DaAST and DaJHAMT were analyzed by qRT-PCR at several time points after JHA treatment. We first examined the effects of JHA application in larvae. The qRT-PCR analysis showed that both doses ( 5 and $100 \mu \mathrm{g} / \mu \mathrm{L}$ of methoprene) of JHA application significantly influenced the expression of DaAST and DaJHAMT $(p<0.05)$ (Figure 5). JHA treatments increased the DaAST and DaJHAMT expressions from 0 to $24 \mathrm{~h}$ at both doses $(5 \mu \mathrm{g} / \mu \mathrm{L}$ and $100 \mu \mathrm{g} / \mu \mathrm{L})$, then increased expression from 24 to $72 \mathrm{~h}$ post treatment (Figure $5 \mathrm{~A}, \mathrm{C}$ ). The expression of DaJHAMT was upregulated from 0 to $48 \mathrm{~h}$ after treatment $(25 \mu \mathrm{g} / \mu \mathrm{L})$, compared with the larvae controls. The expression of DaAST and DaJHAMT between larvae treated with different doses only differed significantly at $24 \mathrm{~h}$ post treatment. Next, we examined the effects of JHA application on pupae. Compared with the pupae of the control group, there was no significant difference in the expression of $D a A S T$ at different times at all doses (Figure 5B). The expression of DaJHAMT in the $5 \mu \mathrm{g} / \mu \mathrm{L}$ treatment group increased with time until $72 \mathrm{~h}$ post treatment, however, there was no significant difference over time for other doses (Figure 5D). The expression levels of DaAST and DaJHAMT between the pupae treated with different doses were only significantly different at $48 \mathrm{~h}$ post treatment, and pupae at a dose of $25 \mu \mathrm{g} / \mu \mathrm{L}$ had the highest expression levels compared with those treated with $5 \mu \mathrm{g} / \mu \mathrm{L}$ and $100 \mu \mathrm{g} / \mu \mathrm{L}$. 

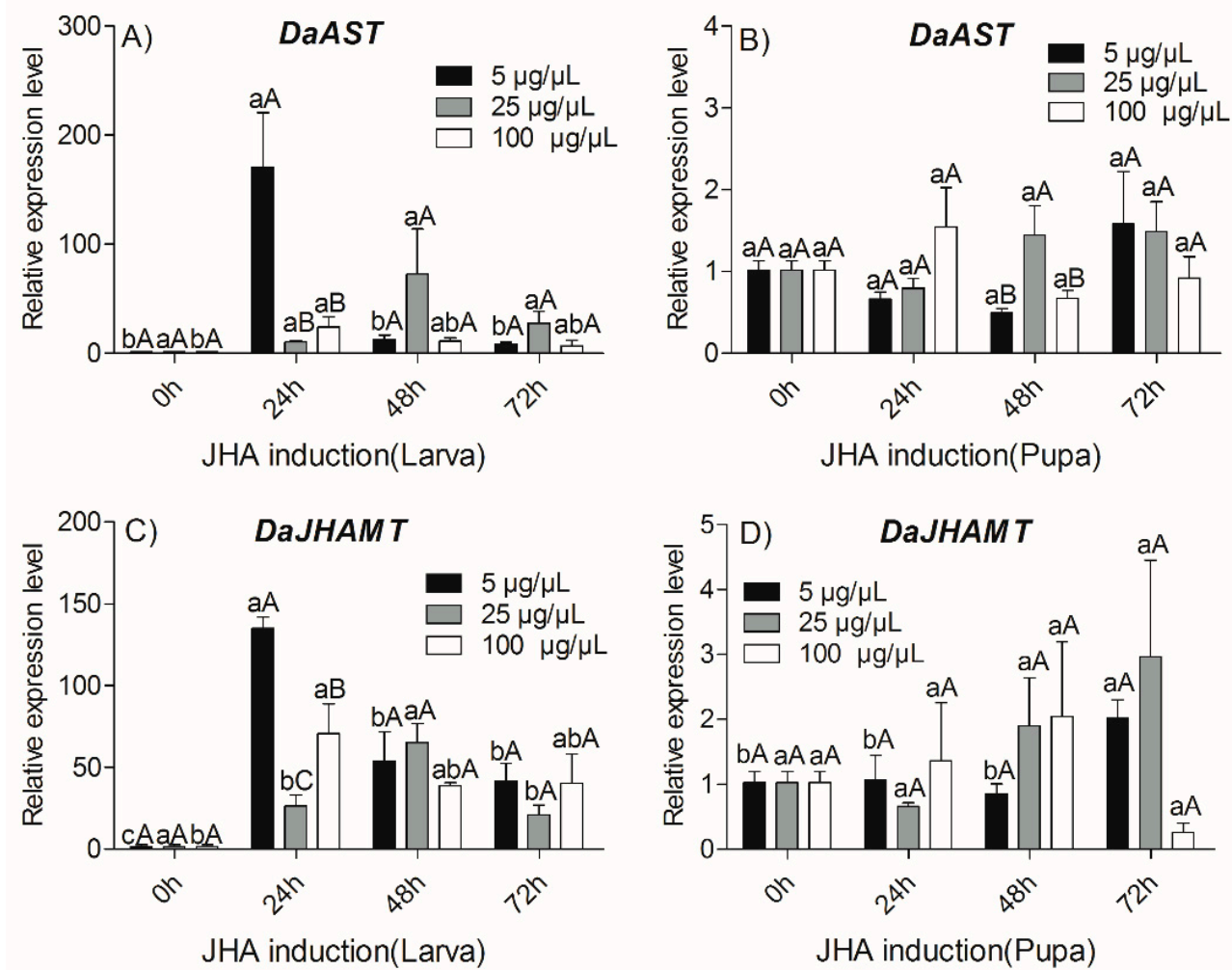

Figure 5. Relative expression of DaAST and DaJHAMT genes with JHA $(5,25,100 \mu \mathrm{g} / \mu \mathrm{L})$ at different times in larvae and pupae. (A) DaAST mRNA level in larvae; (B) DaAST mRNA level in pupae; (C) DaJHAMT mRNA level in larvae and (D) DaJHAMT mRNA level in pupae. The results represent the means \pm SE of three independent experiments. In all graphs, the transcript levels are shown relative to acetone-treated (control) larvae and pupae. All templates were normalized with CYP4G55 and $\beta$-actin. The $2^{-\Delta \Delta \mathrm{Ct}}$ and SE values were used for plotting. Different letters indicate significant differences at $p<0.05$ (two-way ANOVA). Uppercase letters mark significant differences between concentrations at the same time, while lowercase letters mark the significant differences between times at the same concentration.

\subsection{RNAi Effect of DaAST and DaJHAMT}

\subsubsection{Determination of DaAST and DaJHAMT Silencing by qRT-PCR}

Analysis of the expression of DaAST and DaJHAMT after injection with simultaneous dsAST and dsJHAMT confirmed that both genes were successfully knocked down at all stages (Figure 6). For the DaAST and DaJHAMT expression level analysis, compared with the negative control, the transcription levels of DaAST and DaJHAMT measured by qRTPCR at $72 \mathrm{~h}$ were significantly lower than those at $24 \mathrm{~h}(p<0.05)$. These results indicate that RNAi through injection and smearing requires the accumulation of dsRNA in the beetles, and that continuous feeding can inhibit gene expression. These results indicate that $D a A S T$ and $D a J H A M T$ gene silencing can reduce the expression of the target genes. 

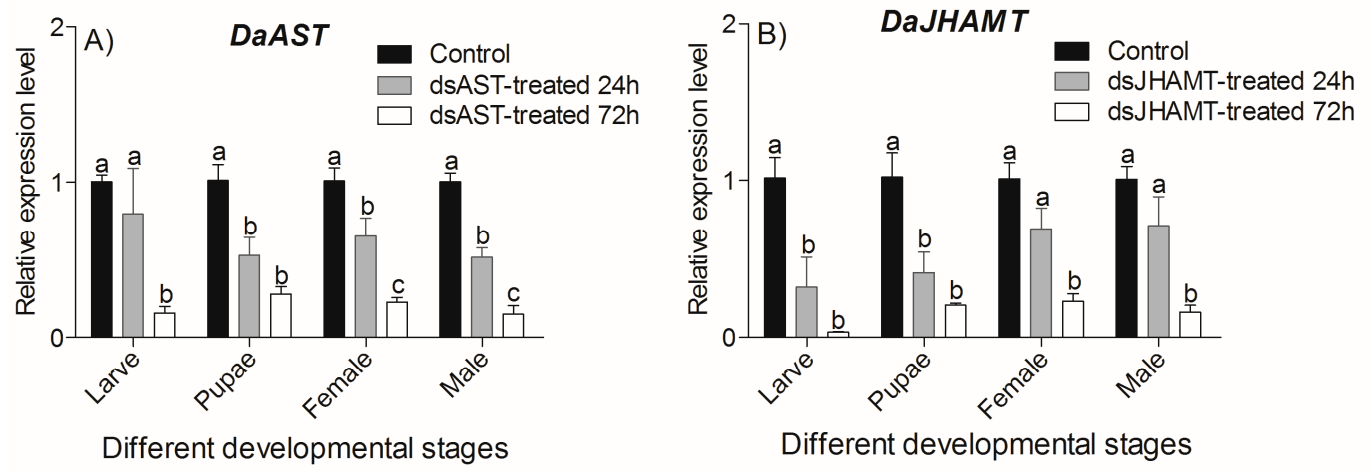

Figure 6. The qRT-PCR analysis of DaAST and DaJHAMT gene transcript patterns in $D$. armandi 24 and $72 \mathrm{~h}$ after dsRNA injection. (A) The qRT-PCR analysis of DaAST transcript pattern; (B) the qRT-PCR analysis of DaJHAMT. The standard errors of the means of three biological replicates are represented by error bars. Different letters above the bars indicate a significant difference (One-way ANOVA, $p<0.05$, with Tukey's test of multiple comparisons).

\subsubsection{Knockdown Effect of Injecting dsAST and dsJHAMT Separately}

In this study, we found that knockdown of DaAST in larvae enhanced the expression of DaHMG-R, DaPMK and DaJHAMT (DaHMG-R: $\mathrm{t}=-4.191, \mathrm{df}=4, p=0.014 ;$ DaPMK: $\mathrm{t}=-5.459, \mathrm{df}=4, p=0.005 ;$ DaJHAMT: $\mathrm{t}=-9.118, \mathrm{df}=4, p=0.001$ ) (Figure 7A), with no significant expression of MVA pathway genes when knocking down DaAST in pupae (Figure 7B). Knockdown of DaAST in females enhanced the expression of DaJHAMT (DaJHAMT: $\mathrm{t}=-4.035, \mathrm{df}=4, p=0.016$ ) (Figure 7C), whereas knockdown of DaAST in males enhanced the expression of DaHMGR and DaJHAMT (DaHMG-R: $\mathrm{t}=-3.574, \mathrm{df}=4$, $p=0.023 ;$ DaJHAMT: $\mathrm{t}=-4.232, \mathrm{df}=4, p=0.013$ ) (Figure 7D).

We found that $D a J H A M T$ deletion in larvae significantly downregulated the expression of the MVA pathway gene DaAACT and DaHMG-R (DaAACT: $\mathrm{t}=5.406, \mathrm{df}=4, p=0.006$; DaHMG-R: $\mathrm{t}=3.407, \mathrm{df}=4, p=0.027$ ) (Figure 7E). We found that knockdown of DaJHAMT in females significantly downregulated the expression of $D a A A C T, D a P M K, D a M P D C$ and DaFPPS (DaAACT: $\mathrm{t}=5.134, \mathrm{df}=4, p=0.007 ;$ DaPMK: $\mathrm{t}=8.983, \mathrm{df}=4, p=0.001 ;$ DaMPDC: $\mathrm{t}=6.999, \mathrm{df}=4, p=0.002 ;$ DaFPPS: $\mathrm{t}=4.921, \mathrm{df}=4, p=0.008$ ) (Figure 7F, but significantly upregulated the expression of DaHMG-S, DaHMG-R and DaMK (DaHMG-S: $\mathrm{t}=-4.416$, $\mathrm{df}=4, p=0.012 ;$ DaHMG-R: $\mathrm{t}=-10.053, \mathrm{df}=4, p=0.001 ;$ DaMK: $\mathrm{t}=-4.682, \mathrm{df}=4$, $p=0.009$ ) (Figure 7G). Knockdown of DaJHAMT in males significantly downregulated the expression of HMGR (DaHMG-R: $\mathrm{t}=3.211, \mathrm{df}=4, p=0.033$ ) (Figure $7 \mathrm{H}$ ).

\subsubsection{The Effects of RNAi of dsAST and dsJHAMT on the Development of D. armandi}

After the larvae were treated with engineered bacteria, the survival rates of the control (vector control), dsAST and dsJHAMT groups were $13.33 \%, 20.00 \%$ and $10.00 \%$, respectively, on Day five (Figure 8A). The Kaplan-Meier method (log rank (Mantel-Cox)) was used to analyze the survival rates. There was no significant difference in the survival rates of the dsAST and dsJHAMT groups compared with the control group (dsAST: $\chi^{2}=0.037$, $\mathrm{df}=1, p=0.847$; dsJHAMT: $\left.\chi^{2}=0.010, \mathrm{df}=1, p=0.919\right)$. After the pupae were treated with engineered bacteria, the survival rates of the control (vector control), dsAST and dsJHAMT groups on Day nine was $60.00 \%, 24.00 \%$, and $48.00 \%$, respectively. (Figure $8 \mathrm{~B}$ ). Survival in the dsAST group was $36 \%$ lower than in the control group $\left(\chi^{2}=5.083, \mathrm{df}=1\right.$, $p=0.024)$ whereas there was no difference in survival between the dsJHAMT and control groups $\left(\chi^{2}=0.651, \mathrm{df}=1, p=0.52\right)$. In addition to the larval and pupal survival rate, the effects of dsAST and dsJHAMT on the emergence rate of pupae and the rate of abnormal morphology in emergent adults were also analyzed. The emergence rates of the dsAST and dsJHAMT groups were both $52.00 \%$. These rates were significantly lower than the emergence rate of the control (vector control), which was $72.00 \%(F=17.0, \mathrm{df}=3, p=0.001)$ (Figure $8 \mathrm{C}$ ). The abnormal morphology rates in emergent adults of the control (vector 
control) and dsJHAMT groups were $16.39 \%$ and $15.45 \%$, respectively. These rates were significantly lower than that of the dsAST groups, which was $54.46 \%(F=38.2, \mathrm{df}=3$, $p<0.001$ ) (Figure 8D). Taken together, these data show that DaAST and DaJHAMT gene silencing was able to disturb the growth and development of D. armandi, and that dsAST had the greatest interference effect.
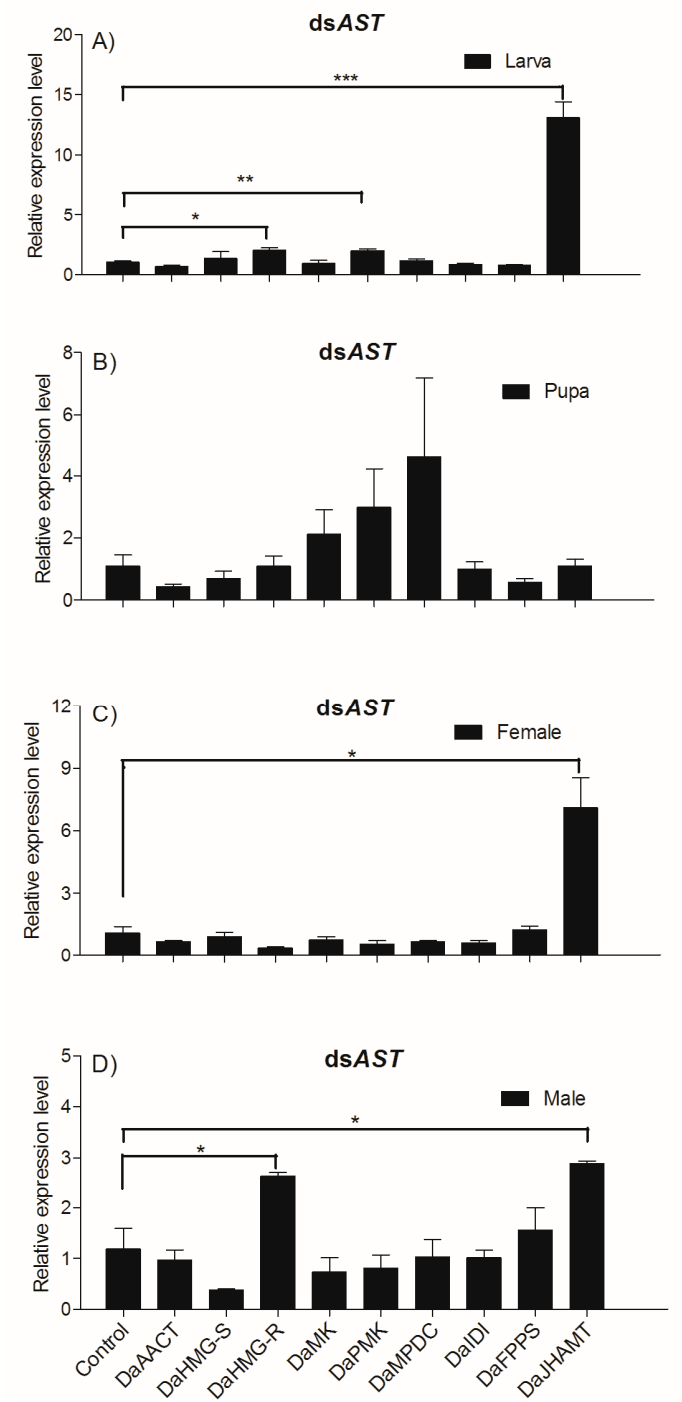
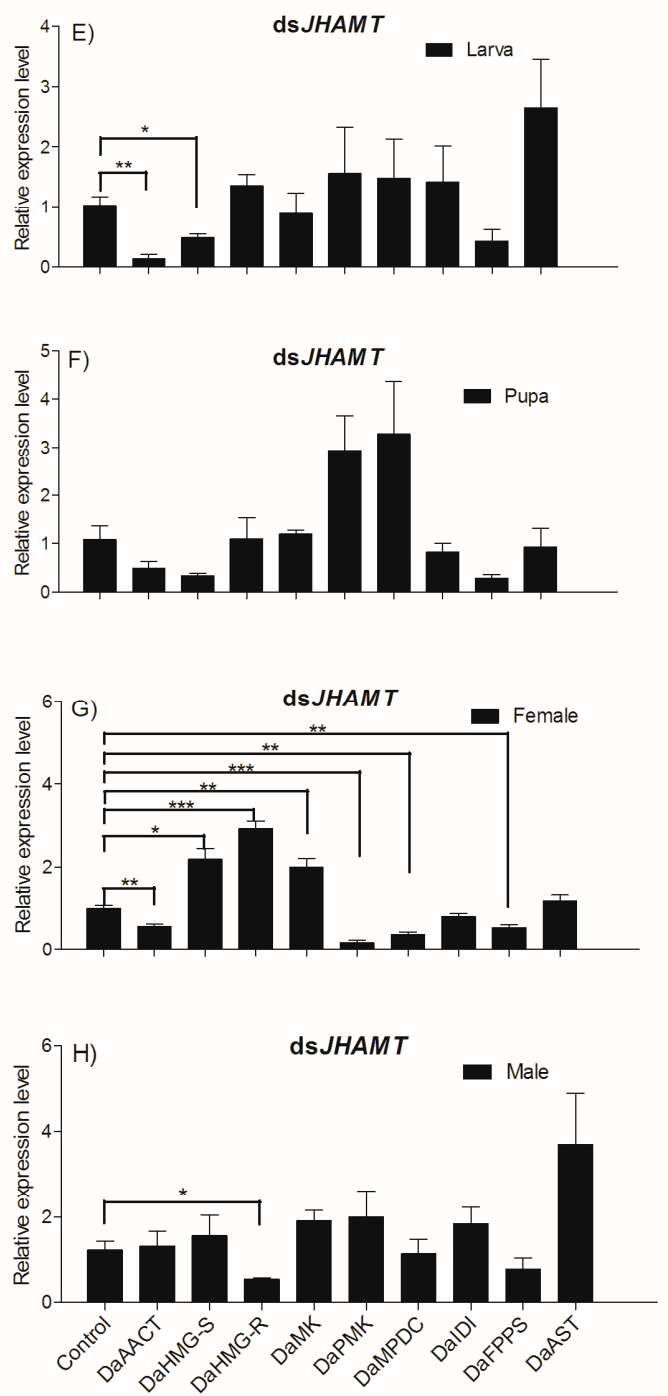

Figure 7. Knockdown of DaAST and DaJHAMT affected JH biosynthesis and the mevalonate pathway. The larvae, pupae and emergent adults were allowed to ingest DEPC treated water (negative control), dsAST or dsJHAMT for three days. The expression levels of DaAST, DaJHAMT and mevalonate enzyme-encoding genes were measured. (A) Knocked down DaAST in larvae, (B) knocked down $D a A S T$ in pupae, (C) knocked down DaAST in female adults, (D) knocked down DaAST in male adults, (E) knocked down DaJHAMT in larvae, (F) knocked down DaJHAMT in pupae, (G) knocked down DaJHAMT in female adults and $(\mathbf{H})$ knocked down DaJHAMT in male adults. The columns represent averages with vertical lines indicating SE. Asterisks denote significant differences (unpaired $t$-test; ${ }^{*} p<0.05,{ }^{* *} p \leq 0.01,{ }^{* * *} p \leq 0.001$ ). 

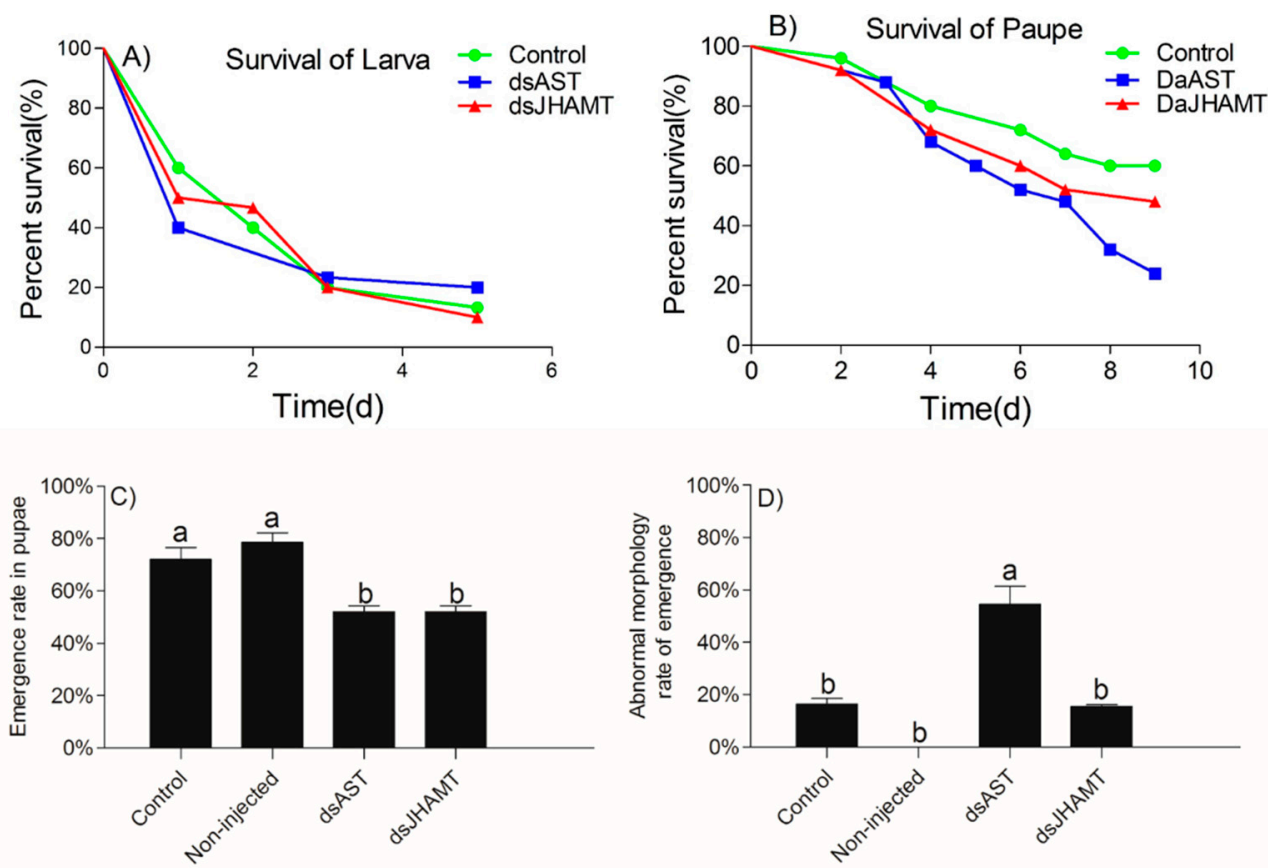

Figure 8. Survival emergence and abnormal morphology rate in D. armandi larvae and pupae after RNAi. Effect of bacterially expressed dsAST/JHAMT on D. armandi larvae and pupae. (A) Survival rate in larvae, (B) survival rate in pupae, (C) emergence rate in pupae and (D) abnormal morphology rate in pupae. There were 25 samples in each biological repetition. The data were analyzed by a one-way ANOVA test. Different letters above the bars indicate a significant difference $(p<0.05)$.

\subsubsection{Adult Development of the dsRNA Phenotypes}

Figure 9 shows the phenotypes of $D$. armandi adults produced by dsRNA-mediated transcript silencing. The injection of pupae with dsRNA for DaAST resulted in shape abnormalities in $54.46 \%$ of the treated beetles. Many parts of their appendices, including the wings and parts of the legs, were deformed or partly covered with old epicuticle. The abnormal morphology rate in emergent adults in the control group (vector control) was significantly lower by $38.07 \%$ than in those of the dsAST groups, and the abnormal adults died within 4 days after emergence. The beetles with intact cuticles did not differ in shape from the controls. Moreover, the DaAST dsRNA-treated beetles had smaller heads and bodies, but the elytra were shorter only in deformed beetles (Table 3).

Table 3. Adult development of the dsRNA phenotypes.

\begin{tabular}{ccccc}
\hline Groups & $\begin{array}{c}\text { Emergence } \\
\mathbf{( \% )}\end{array}$ & $\begin{array}{c}\text { Adult } \\
\text { Deformity (\%) }\end{array}$ & $\begin{array}{c}\text { Death of Deformed } \\
\text { Adults (\%) }\end{array}$ & $\begin{array}{c}\text { Days of Death } \\
\text { (d) }\end{array}$ \\
\hline Control & 72.00 & 16.39 & 66.67 & 4 \\
Non-injected & 78.67 & 1.33 & 100 & 3 \\
dsAST & 52.00 & 54.46 & 71.42 & 1 \\
dsJHAMT & 52.00 & 15.45 & 100 & 2 \\
\hline
\end{tabular}

Injection of dsRNA for DaJHAMT into pupae of D. armandi resulted in the production of about $15.45 \%$ deformed adults (Figure 9). Although there was no difference in the rate of adult emergence between intact and deformed beetles, the misshaped beetles died within two days of adult life. The elytra of the deformed beetles were much shorter in length compared with the controls and were neither tanned nor sclerotized (Figure 9). 


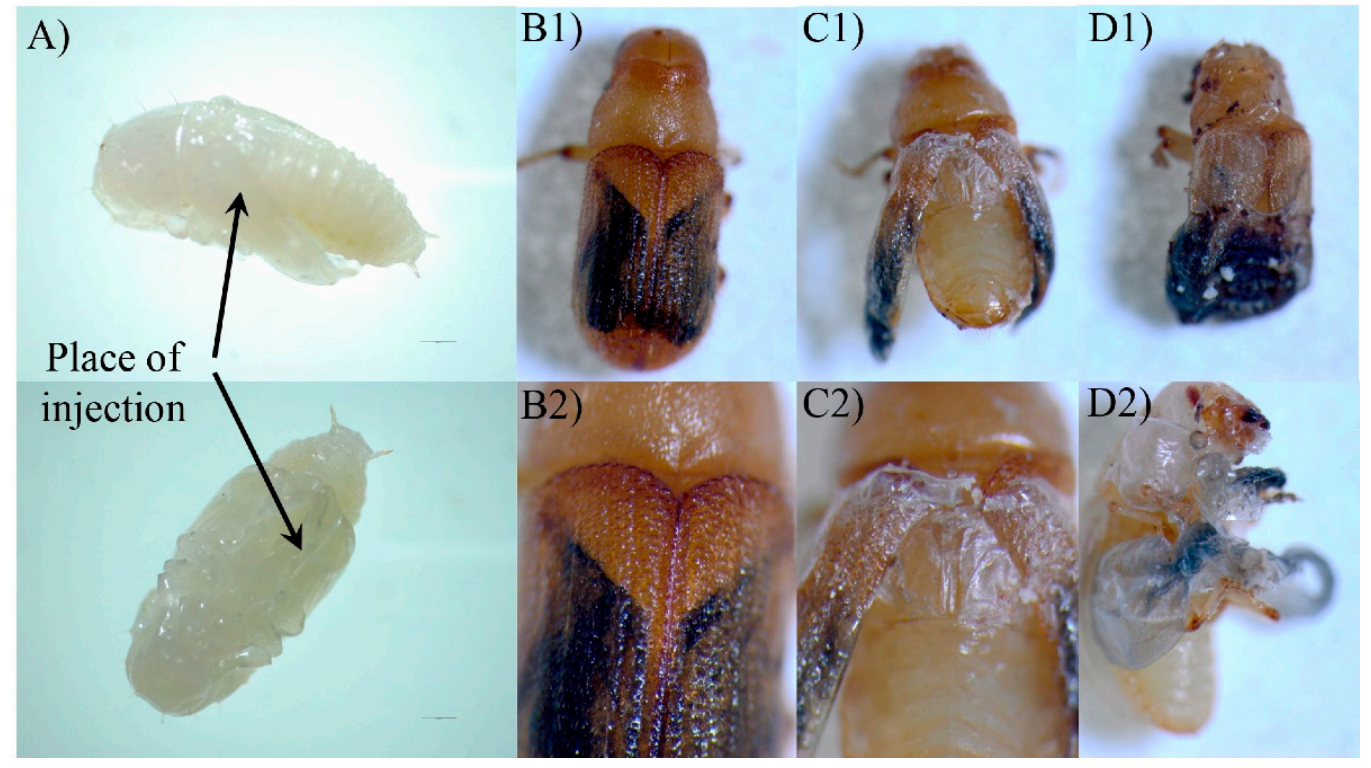

Figure 9. Biological morphology of D. armandi from the pupa to adult stage. (A) Arrows point to the place of pupa injection; (B1,B2) normal adult morphology in the control group; $(\mathbf{C} 1, \mathbf{C} 2)$ abnormal morphology of adult D. armandi that were treated with dsAST; (D1,D2) abnormal morphology of adult $D$. armandi after dsJHAMT treatment.

The frontalin content of adult males differed significantly among treatment groups (one-way ANOVA: $F=21.877, \mathrm{df}=2, p=0.002$ ) (Figure 10). Injection of DaJHAMT dsRNA significantly reduced the frontalin content to zero. However, injection of DaAST dsRNA had no significant effect on the amount of frontalin produced by male adults.

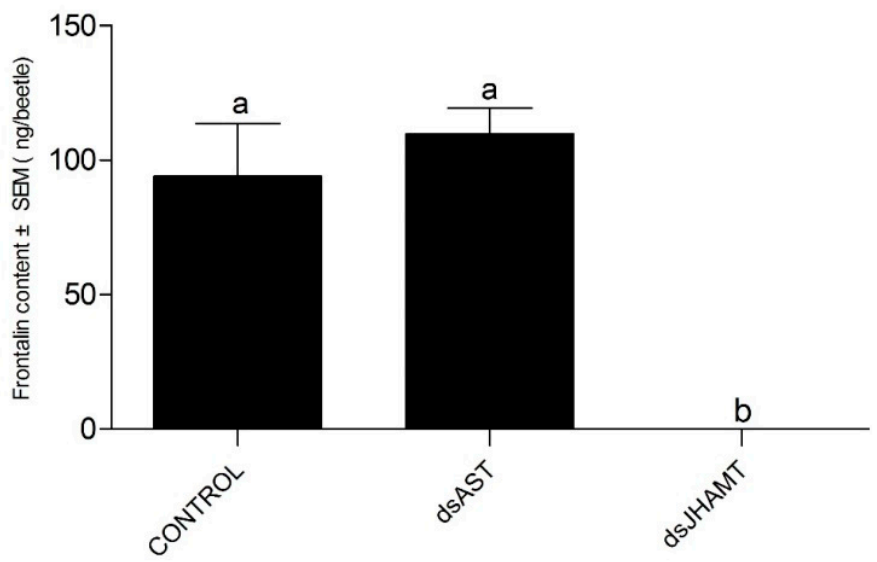

Figure 10. Knockdown of DaAST and DaJHAMT affected frontalin biosynthesis. Frontalin levels in male adults injected with dsRNA for the DaAST and DaJHAMT genes. Different letters above the bars indicate a significant difference (one-way ANOVA, $p<0.05$, with Tukey's test for multiple comparisons).

\section{Discussion}

In this study, allatostatin (AST) and juvenile hormone acid O-methyltransferase (JHAMT) genes identified in D. armandi were analyzed for their expression and function. The PISCF gene encodes a biological peptide that appears to be highly conserved compared with other heterologous proteins. For example, the peptide identified in T. castaneum (TricaPISCF) also seems to be identical to the Tenebrio molitor sequence (Tenmo-PISCF) $[43,66]$. DaJHAMT displays the characteristic sequence of a SAM-dependent methyltransferase, 
which shows the structure of the active site for binding SAM and transferring the methyl group to FA or JHA [67].

$D a A S T$ was highly expressed after each molt in the pupal stage and during adult migration, while DaJHAMT was highly expressed on the third day of the larval stage. Because of their role in regulating $\mathrm{JH}$ biosynthesis, food uptake and visceral muscle contraction, AST peptides are also known as "brain-gut peptides" [68]. Consistent with its function, $D a A S T$ is usually mainly expressed in the brain. Real-time PCR showed that DaAST was abundantly expressed in the brains of pupae; lower expression values were found in the heads of larvae and adults, but increased expression was found in the intestines of larvae and adults. Similarly, ASTC of L. decemlineata and T. castaneum were also predominantly distributed in the brain + CC/CA complex and intestines [42,43].

This study found that after the application of JHA, the mRNA levels of several key genes involved in JH biosynthesis in insects, such as AST and JHAMT, were regulated by $\mathrm{JH}$ biosynthesis in insects after JHA administration. JHAMT is the most important regulator of the JH biosynthesis process [69]. The qRT-PCR results showed that the application of low concentrations of JHA stimulated the expression of DaAST in D. armandi larvae but suppressed the expression of DaJHAMT in D. armandi pupae. Meanwhile, low concentrations of JHA stimulated DaJHAMT expression in D. armandi larvae but suppressed DaJHAMT expression in pupae, which is consistent with observations in Galeruca daurica [70] and Colaphellus bowringi [71]. Thus, a negative feedback loop appears to control the relation between hemolymph JH titers and AST in Diploptera punctata: a higher JH titer in hemolymph stimulates AST gene expression, and then functional AS peptides inhibit JH biosynthesis and release in CA [72]. JH negatively feeds back to regulate the endocrine glands, which induce their products themselves. The direct or indirect inhibition of JH biosynthesis by CA first appeared in studies evaluating the effects of $\mathrm{JH}$ analogs. Topical application of such analogs inhibited JH biosynthesis in a dose-dependent manner, as did topical treatment with $\mathrm{JH}$ itself [72]. These results indicated that exogenous JH analogs paracrine release of $A S T$ in intact calcium and act via the hemolymph in unconnected calcium to inhibit $\mathrm{JH}$ biosynthesis in the brain [73,74].

RNAi was introduced to assess the possible effects of DaAST and DaJHAMT on JH biosynthesis in D. armandi. After injection with dsAST or dsJHAMT, the expression of the target gene dsAST/dsJHAMT was knocked down in larvae, pupae and adults, indicating the success of RNAi. When $D$. armandi larvae and adults ingested dsDaAST, the mRNA level of DaJHAMT increased significantly. In addition, when dsDaAST was knocked down in pupae, there was no significant difference in the expression of mevalonate pathway related genes. This result indicates that $D a A S T$ directly or indirectly affects the activity or expression of DaJHAMT $[43,75,76]$, thereby inhibiting JH biosynthesis in insects [77]. This is consistent with the findings in Spodoptera frugiperda and Clostera anastomosis [78,79].

The injection of dsRNA into freshly molted $D$. armandi pupae resulted in the specific knockdown of the corresponding gene, and this dsRNA-mediated silencing resulted in a loss of a function in the adult phenotype. All adults that appeared were mobile and had well-differentiated adult-like appendages, but some beetles retained an unhardened and untanned stratum corneum and incompletely spread wings. Based on the present results, the hypothetical effects of DaAST on JH biosynthesis in the pupal stage of $D$. armandi can be speculated. Treatment of early pupae with the JH mimics methoxypentadiene or hydropentadiene, resulting in the formation of a second pupal cuticle during adult molting $[55,80]$. The phenotype is similar to that processed by dsAST-treated phenotypes. Knockout of $A S T$ alone resulted in a significant increase in pupae mortality, a significant decrease in cumulative emergence and a significant malformation in emergent adults. After knockdown of DaJHAMT alone, the mortality rate of pupae increased, the cumulative emergence rate decreased significantly, and the emergence malformation rate did not change significantly. These results indicate that DaAST inhibits JH biosynthesis in $D$. armandi. However, these results did not contribute to determining whether $D a A S T$ regulates $\mathrm{JH}$ biosynthesis in larvae, as DaAST is not only expressed in the brain; the increased 
mortality could be due to something other than JH or JHAMT. In male adults, knockdown of DaJHAMT but not DaAST led to a dramatic decrease in frontalin synthesis. This suggests that in adult males, $D a A S T$ does not directly inhibit JH synthesis, since the negative effects of DaAST gene silencing in D. armandi may also be caused by their myoregulatory properties and other putative functions [32,81,82].

\section{Materials and Methods}

\subsection{Insects}

We collected Pinus armandii Franch infested with D. armandi on the southern slopes of the central Qinling Mountains $\left(33^{\circ} 18^{\prime}-33^{\circ} 28^{\prime} \mathrm{N}, 108^{\circ} 21^{\prime}-108^{\circ} 39^{\prime} \mathrm{E}\right.$ ) in Shaanxi, China, and placed the specimens in a greenhouse. The adult insects were collected after they emerged and were stored on moist paper at $4{ }^{\circ} \mathrm{C}$. The sex of adults was based on external genitalia and male-specific auditory cues $[83,84]$. Larvae and pupae were collected from under the bark of infected $P$. armandii.

\section{2. $R N A$ Isolation and $c D N A$ Synthesis}

Total RNA was isolated from three beetles by the UNIQ-10 Column Trizol Total RNA Isolation Kit (Sangon Biotech, Shanghai, China) in accordance with the manufacturer's protocol. Its integrity was checked on 1\% agarose gels and quantified using NANO DROP 2000 spectrophotometry (Thermo Scientific, Pittsburgh, PA, USA). The purity was calculated by means of the A260/A280 ratio $(\mu \mathrm{g} / \mathrm{mL}=\mathrm{A} 260 \times$ dilution factor $\times 40)$. The synthesized cDNA obtained from the sample was used as the template with the TransScript One-Step gDNA Removal and cDNA Synthesis SuperMix (TransGen Biotech, Beijing, China).

\subsection{Amplification of Genes, Cloning and Sequence Analyses}

cDNA synthesized from the sample was used as a template for the PCR reaction. Specific primers (Table S1) were designed in Primer Premier 5.0, based on the AST and JHAMT sequences of D. ponderosae from NCBI (http:/ / www.ncbi.nlm.nih.gov/, accessed on 12 February 2021). PCR amplifications were performed in a C1000 thermocycler (BioRad, Hercules, CA, USA), and the cDNA amplification was carried out in a $20 \mu \mathrm{L}$ reaction volume: $1 \mu \mathrm{L}$ cDNA, $0.25 \mu \mathrm{M}$ of each primer, and $10 \mu \mathrm{L}$ EcoTaq PCR SuperMix (TransGen Biotech, Beijing, China), with $\mathrm{ddH}_{2} \mathrm{O}$ added to $20 \mu \mathrm{L}$. The reaction conditions were as follows: $94{ }^{\circ} \mathrm{C}$ for $5 \mathrm{~min}, 30$ cycles of $94{ }^{\circ} \mathrm{C}$ for $30 \mathrm{~s}$, TM of each pair of primers for $30 \mathrm{~s}$ and $72{ }^{\circ} \mathrm{C}$ for $30 \mathrm{~s}$, with a final extension for $10 \mathrm{~min}$ at $72{ }^{\circ} \mathrm{C}$. The PCR products were visualized on $1 \%$ agarose gels stained with $1 \times$ DuRed and compared with a $2 \mathrm{~K}$ plus DNA marker (TransGene Biotech, Beijing, China).

Single-stranded 5'and $3^{\prime}$ RACE-ready cDNA was synthesized from RNA using a SMARTer RACE cDNA Amplification Kit (Clontech Laboratories Inc., Mountain, CA, USA) according to the manufacturer's protocol. Partial sequences were used in the primer design, and the PCR was performed as described in the SMARTer ${ }^{\mathrm{TM}}$ RACE cDNA Amplification Kit (Clontech Laboratories Inc., Mountain, CA, USA). The amplicons were purified, cloned and sequenced. Sequences were manually edited with EditSeq from DNASTAR (https: //www.dnastar.com/, accessed on 6 March 2021) to obtain inserts, which were then BLASTed against the NCBI database. The complete sequences were compared using a BlastP search with those deposited in GenBank [62].

\subsection{Sequence Analyses of the Genes}

The molecular mass $(\mathrm{kDa})$ and the isoelectric point (IP) of the two sequences were determined by the ProtParam program [63]. DaAST and DaJHAMT of D. armandi were checked for likely subcellular localization using Target P1.1 software (http:/ / www.cbs.dtu. $\mathrm{dk}$ /services/TargetP/, accessed on 21 March 2021) with the default parameters [64].

In order to identify AST and JHAMT in D. armandi, a phylogenetic inference analysis of 11 full-length sequences was performed by the neighbor-joining method with 
MEGA7.0 [85,86]. To estimate the support for each node, bootstrap values were calculated after 1000 pseudoreplicates.

\subsection{Analysis of the DaAST and DaJHAMT Genes Transcript Levels (Real Time-qPCR)}

\subsubsection{Expression Patterns of Different Life Stages and Tissues}

During development, D. armandi larvae were separated into three sub-stages: small larvae (SL: earlier instar larva whose weight is less than $2.5 \mathrm{mg}$ ); large larva (LL: large one is final instar larva but still feeding and the weight of the larva is between 5.0 and $7.0 \mathrm{mg}$ ); mature larvae (ML: when they stopped feeding in preparation for pupation). Pupae were separated into five sub-stages: P0: pupae, P1: Day 1 of the pupal stage, P2: Day 2 of the pupal stage, P3: Day 3 of the pupal stage and P4: Day 4 of the pupal stage. D. armandi adults were separated into four sub-stages: teneral adults (TA: body color still light), dark brown adults (DbA: decayed feather hole, body color was dark brown), emergent adults (EA), and feeding adults (invading a new host) There were three biological replicates per developmental stage, each containing three insects [83].

In terms of tissue distribution, for tissue-specific analysis of DaAST and DaJHAMT genes, 60 males and 60 females at the emergent adult stage (head, anterior midgut, hindgut, Malpighian tubule, fat body, reproductive organ (testes of males and ovaries of females) and antennae), 30 larvae and 30 pupae (head, gut, fat body, epidermis) were dissected, frozen immediately in liquid nitrogen and stored at $-80^{\circ} \mathrm{C}$. Each tissue was replicated three times, and a pool of total RNA extracted from different tissues was used per replicate. RNA isolation and cDNA synthesis followed the protocols described above.

\subsubsection{Effects of JHA Injection on Transcript Levels of DaAST and DaJHAMT}

Solutions of the original juvenile hormone analog JHA methoprene (Sigma, Saint Louis, MO, USA), were separately diluted to 5,25 and $100 \mu \mathrm{g} / \mu \mathrm{L}$ concentrations using acetone [87]. Next, $0.1 \mu \mathrm{L}$ of each JHA dilution was injected into $D$. armandi larvae and pupae through the ventral abdomen using Hamilton Microliter syringes (700 series, RN) with 32G sharp-point needles (Hamilton, Switzerland) to a final JHA content of 0.5, 2.5 or $10 \mu \mathrm{g}$. Meanwhile, an equal amount of acetone was injected as the solvent control. To analyze the expression of the JH-induced genes, the total RNA was extracted after $0,24,48$ and $72 \mathrm{~h}$ of JHA or acetone treatment and subjected to cDNA synthesis and qRT-PCR.

\section{6. dsRNA Synthesis \\ 4.6.1. Target Genes}

The AST and JHAMT genes of D. armandi were identified in a previous clone. Partial sequences of the DaAST and DaJHAMT genes (GenBank Accession No: MW645339 and MW645341) were appended with NotI and XbaI. The DaAST and DaJHAMT sequences were amplified with primers (Table S1) using EcoTaq PCR SuperMix (TransGen Biotech, Beijing, China) and a C1000 thermo cycler (Bio-Rad, Hercules, CA, USA). The polymerase chain reaction (PCR) amplification reaction conditions were as mentioned earlier.

\subsubsection{Vector Construction and Expression}

\section{Construction of transformed E. coli expressing dsRNA}

PCR products obtained in the previous steps were excised and cloned into the plasmid vector L4440 (Wuhan Miaoling Biotechnology Co., Ltd., Wuhan, China), between the NotI and $\mathrm{XbaI}$ restriction sites. Successful cloning was verified through PCR and sequencing. Plasmids containing the correct insert were extracted and transformed into E. coli strain HT115 (DE3) (Shanghai Weidi Biotechnology Co., Ltd., Shanghai, China). Positive clones were incubated at $37^{\circ} \mathrm{C}$ until the mid-exponential phase (OD600 $\left.=0.4\right)$. To activate the T7 promoter for RNA transcription, IPTG (isopropyl- $\beta$-D-1-thiogalactopyranoside) was added to a final concentration of $0.8 \mathrm{mM}$ and then incubated for an additional $4 \mathrm{~h}$ under the same conditions. Each bacterial culture $(100 \mathrm{~mL})$ was transferred into a 50-mL Falcon tube and centrifuged at $4000 \times g$ for $10 \mathrm{~min}$ at $4{ }^{\circ} \mathrm{C}$. 


\section{Isolation of dsRNA using conventional method}

Cells were harvested via centrifugation at $5000 \times g$ and $4{ }^{\circ} \mathrm{C}$ for $10 \mathrm{~min}$. DsRNA was isolated from $1 \mathrm{~mL}$ of the cell suspension with the UNIQ-10 Column Trizol Total RNA Isolation Kit (Sangon Biotech, Shanghai, China) according to the manufacturer's protocol. The extracted RNA was compared with the dsRNA not induced by IPTG to determine whether IPTG had been successfully induced. Its integrity was checked on 1\% agarose gels, and quantification was performed by spectrophotometry with a NANO DROP 2000 (Thermo Scientific, Pittsburgh, PA, USA). The reactions were allowed to proceed overnight at $42{ }^{\circ} \mathrm{C}$, followed by both the RNase and DNase digestion and purification steps to obtain the dsRNA. The dsRNA was spectrophotometrically quantified before injection

Based on the L4440 vector, two expression vectors, L4440-AST and L4440-JHAMT, corresponding to DaAST and DaJHAMT, were constructed. The plasmids were digested by the restriction endonuclease NotI and $\mathrm{XbaI}$. The gel electrophoresis results indicated that there were two bands; one is about $390 \mathrm{bp}$ from L4440-AST, and the other $570 \mathrm{bp}$ from L4440-JHAMT. After HT115 harbouring the plasmids, L4440-AST or L4440-JHAMT was induced by IPTG; we extracted the total RNA (containing dsAST or dsJHAMT) from the engineered bacteria (Figure S1). The gel electrophoresis results showed that the remainder was the band of dsAST and dsJHAMT (Figure S1).

\subsubsection{RNAi Experiment}

Larvae and pupae were collected under the bark of infected P. armandii. Male and female beetles were sexed upon emergence on the basis of external genitalia and malespecific auditory cues $[83,84]$ and used in experiments immediately after sexing. For RNAi exposure, synthesized dsRNA $(0.2 \mu \mathrm{L}$, concentration: $1000 \mathrm{ng} / \mu \mathrm{L})$ was injected into the ventral abdomen of the larvae on the first day of the last instar or of pupae using a $10 \mu \mathrm{L}$ Hamilton Microliter syringes (700 series, RN) with 32G sharp-point needles (Hamilton, Switzerland). Individual adult beetles $(\mathrm{N}=25)$ were injected with two separate dsRNA treatments (AST or JHAMT) of $0.2 \mu \mathrm{L}$ (concentration: $1000 \mathrm{ng} / \mu \mathrm{L}$ ). Following dsRNA ingestion, beetles from each treatment were placed together in petri dishes containing damp filter paper; dishes were oriented vertically and maintained at $23{ }^{\circ} \mathrm{C}$ in the dark. Beetles were evaluated after $24 \mathrm{~h}$. DEPC-treated water was used as a negative control. Untreated beetles were used as blank controls. Each beetle was injected only once. For each dose, three of the treated beetles were randomly selected at $24 \mathrm{~h}$ and $72 \mathrm{~h}$, frozen immediately in liquid nitrogen and stored at $-80{ }^{\circ} \mathrm{C}$ for further experiments. The expression levels of DaAST were quantified first, and the expression of DaJHAMT was quantified only in beetles in which AST was successfully knocked down. Twenty-five larvae were observed and the survival rate was recorded, and 25 pupae were observed for defective wings after plumentation and repeated three times.

\subsubsection{RNA Interference and Quantification of Frontalin}

In order to understand the effects of DaAST and DaJHAMT on the pheromone biosynthesis of male D. armandi, D. armandi males were injected with $200 \mathrm{ng}$ of dsRNA (concentration: $1000 \mathrm{ng} / \mu \mathrm{L}$ ) through the ventral abdomen using Hamilton Microliter syringes (700 series, RN) with 32G sharp-point needles (Hamilton, Switzerland). Beetles were treated according to the method of Sun et al. (2021) [88]; GC-MS determination also followed the methodology of Sun et al. to detect the content of frontalin $[84,88,89]$.

\subsection{Real-Time PCR}

Specific qRT-PCR primers were designed by Primer Premier 5.0 on the basis of the obtained nucleotide sequences (Table S1). The melting curve analysis was performed to ensure that only a single product corresponding to the target sequence was amplified. All primer pairs were tested in advance to obtain close to $100 \%$. The expression of the CYP4G55 [90] and $\beta$-actin [83] genes was used as an internal control. Real-time PCR was performed in triplicate according to the manufacturer's instructions using TransStart Top 
Green qPCR SuperMix (TransGen Biotech, Beijing, China) on a CFX96TM Real-Time qPCR Detection System (Bio-Rad, Hercules, CA, USA). The qPCR was performed using the following program: $95^{\circ} \mathrm{C}$ for $10 \mathrm{~min} ; 40$ cycles at $95^{\circ} \mathrm{C}$ for $5 \mathrm{~s}$, $\mathrm{TM}$ of each pair of primers (Table S1) for $15 \mathrm{~s}$ and $72{ }^{\circ} \mathrm{C}$ for $20 \mathrm{~s}$.

\subsection{Statistics}

The $2^{-\Delta \Delta C t}$ method was used to determine the effect of interference. According to this rule of thumb, transcript levels lower than 0.5 was considered to show that the effect of RNAi was significant. One-way analysis of variance (ANOVA) $(p<0.05)$ and two-way analysis was used to determine the significance of different treatments, and Tukey's test was used to identify differences among treatments. For the gene silencing analysis, an unpaired $t$-test was used to compare differences in JH biosynthesis genes. The Kaplan-Meier method (log rank (Mantel-Cox)) was used to analyze the survival rates $(p<0.05)$ [91]. All statistical analyses were performed using SPSS Statistics 21.0 (IBM, Chicago, IL, USA) and plotted using Prism 5.0 (GraphPad Software, San Diego, CA, USA).

\section{Conclusions}

In general, injection of dsAST significantly increased the expression of DaJHAMT in larvae and adults, but had no significant effect on the pupae. Injection of dsAST and dsJHAMT had no significant effect on larval survival. Injection of dsAST and dsJHAMT into pupae resulted in decreased emergence rates, but dsAST resulted in approximately $50 \%$ greater susceptibility to deformation than dsJHAMT. Knockdown of DaAST seemed to enhance JH biosynthesis in pupae. In male adults, the intake of dsJHAMT reduced frontalin synthesis to zero, but injection of dsAST had no effect on frontalin synthesis.

Supplementary Materials: The following supporting information can be downloaded at: https: //www.mdpi.com/article/10.3390/ijms23052749/s1.

Author Contributions: Conceptualization, Y.S. and H.C.; methodology, Y.S.; software, D.F.; validation, Y.S., H.C. and D.F.; formal analysis, Y.S.; investigation, B.L.; resources, L.W.; data curation, Y.S.; writing — original draft preparation, Y.S.; writing—review and editing, H.C.; visualization, H.C.; supervision, H.C.; project administration, H.C.; funding acquisition, H.C. All authors have read and agreed to the published version of the manuscript.

Funding: This research was funded by the NATIONAL NATURAL SCIENCE FOUNDATION OF CHINA, grant No. 31870636.

Institutional Review Board Statement: Not applicable.

Informed Consent Statement: Not applicable.

Data Availability Statement: The datasets generated during and/or analyzed during the current study are available from the corresponding author on reasonable request.

Acknowledgments: We acknowledge support during collection of the insects from Huangguan Forest Farm of Ningxi Forestry Bureau, Shaanxi, China.

Conflicts of Interest: The authors declare that they have no conflict of interest.

\section{References}

1. De Wilde, J.; de Boer, J.A. Humoral and nervous pathways in photoperiodic induction of diapause in Leptinotarsa decemlineata. J. Insect Physiol. 1969, 15, 661-675. [CrossRef]

2. De Loof, A.; de Wilde, J. Hormonal control of synthesis of vitellogenic female protein in the Colorado beetle, Leptinotarsa decemlineata. J. Insect Physiol. 1970, 16, 1455-1466. [CrossRef]

3. Schooneveld, H.; Otazo Sanchez, A.; de Wilde, J. Juvenile hormone-induced break and termination of diapause in the Colorado potato beetle. J. Insect Physiol. 1977, 23, 689-696. [CrossRef]

4. Kramer, S.J. Age-dependent changes in corpus allatum activity in vitro in the adult Colorado potato beetle, Leptinotarsa decemlineata. J. Insect Physiol. 1978, 24, 461-464. [CrossRef]

5. Dortland, J.F. The hormonal control of vitellogenin synthesis in the fat body of the female Colorado potato beetle. Gen. Comp. Endocrinol. 1979, 38, 332-344. [CrossRef] 
6. Vermunt, A.M.W.; Koopmanschap, A.B.; Vlak, J.M.; de Kort, C.A.D. Expression of the juvenile hormone esterase gene in the Colorado potato beetle, Leptinotarsa decemlineata: Photoperiodic and juvenile hormone analog response. J. Insect Physiol. 1999, 45, 135-142. [CrossRef]

7. Dominguez, C.V.; Maestro, J.L. Expression of juvenile hormone acid O-methyltransferase and juvenile hormone synthesis in Blattella germanica. Insect Sci. 2018, 25, 787-796. [CrossRef]

8. Goodman, W.G.; Granger, N.A. The Juvenile Hormones. Compr. Mol. Insect Sci. 2005, 3, 319-408.

9. Noriega, F.G. Juvenile hormone biosynthesis in insects: What is new, what do we know, and what questions remain? Int. Sch. Res. Not. 2014, 2014, 1-16. [CrossRef]

10. Belles, X.; Martin, D.; Piulachs, M.D. The mevalonate pathway and the synthesis of juvenile hormone in insects. Annu. Rev. Entomol. 2005, 50, 181-199. [CrossRef] [PubMed]

11. Diaz, M.E.; Mayoral, J.G.; Priestap, H.; Nouzova, M.; Rivera-Perez, C.; Noriega, F.G. Characterization of an isopentenyl diphosphate isomerase involved in the juvenile hormone pathway in Aedes aegypti. Insect Biochem. Mol. Biol. 2012, 42, $751-757$. [CrossRef] [PubMed]

12. Yu, J.; Dai, L.; Zhang, R.; Li, Z.; Pham, T.; Chen, H. Isolation and expression of HMG-CoA synthase and HMG-CoA reductase genes in different development stages, tissues and treatments of the Chinese white pine beetle, Dendroctonus armandi (Curculionidae: Scolytinae). Comp. Biochem. Physiol. Part B 2015, 187, 62-70. [CrossRef] [PubMed]

13. Sun, Y.; Dai, L.; Kang, X.; Fu, D.; Gao, H.; Chen, H. Isolation and expression of five genes in the mevalonate pathway of the Chinese white pine beetle, Dendroctonus armandi (Curculionidae: Scolytinae). Arch. Insect Biochem. Physiol. 2020, 106, e21760. [CrossRef]

14. Goodman, W.G.; Cusson, M. The Juvenile Hormones. In Insect Endocrinology; Gilbert, L.I., Ed.; Elsevier: San Diego, CA, USA, 2012; pp. 310-365.

15. Wen, D.; Rivera-Perez, C.; Abdou, M.; Jia, Q.; He, Q.; Liu, X.; Zyaan, O.; Xu, J.; Bendena, W.G.; Tobe, S.S.; et al. Methyl Farnesoate plays a dual role in regulating Drosophila metamorphosis. PLoS Genet. 2015, 11, e1005038. [CrossRef] [PubMed]

16. Zhang, J.; Wen, D.; Li, E.Y.; Palli, S.R.; Li, S.; Wang, J.; Liu, S. MicroRNA miR-8 promotes cell growth of corpus allatum and juvenile hormone biosynthesis independent of insulin/IGF signaling in Drosophila melanogaster. Insect Biochem. Mol. Biol. 2021, 136, 103611. [CrossRef]

17. Shinoda, T.; Itoyama, K. Juvenile hormone acid methyltransferase: A key regulatory enzyme for insect metamorphosis. Proc. Natl. Acad. Sci. USA 2003, 100, 11986. [CrossRef] [PubMed]

18. Daimon, T.; Kozaki, T.; Niwa, R.; Kobayashi, I.; Furuta, K.; Namiki, T.; Uchino, K.; Banno, Y.; Katsuma, S.; Tamura, T.; et al. Precocious metamorphosis in the juvenile hormone-deficient mutant of the Silkworm, Bombyx mori. PLoS Genet. 2012, 8, e1002486. [CrossRef] [PubMed]

19. Minakuchi, C.; Namiki, T.; Yoshiyama, M.; Shinoda, T. RNAi-mediated knockdown of juvenile hormone acid O-methyltransferase gene causes precocious metamorphosis in the red flour beetle Tribolium castaneum. FEBS J. 2008, 275, 2919-2931. [CrossRef] [PubMed]

20. Kinjoh, T.; Kaneko, Y.; Itoyama, K.; Mita, K.; Hiruma, K.; Shinoda, T. Control of juvenile hormone biosynthesis in Bombyx mori: Cloning of the enzymes in the mevalonate pathway and assessment of their developmental expression in the corpora allata. Insect Biochem. Mol. Biol. 2007, 37, 808-818. [CrossRef] [PubMed]

21. Minakuchi, C.; Ishii, F.; Washidu, Y.; Ichikawa, A.; Tanaka, T.; Miura, K.; Shinoda, T. Expressional and functional analysis of CYP15A1, a juvenile hormone epoxidase, in the red flour beetle Tribolium castaneum. J. Insect Physiol. 2015, 80, 61-70. [CrossRef] [PubMed]

22. Niwa, R.; Niimi, T.; Honda, N.; Yoshiyama, M.; Itoyama, K.; Kataoka, H.; Shinoda, T. Juvenile hormone acid O-methyltransferase in Drosophila melanogaster. Insect Biochem. Mol. Biol. 2008, 38, 714-720. [CrossRef] [PubMed]

23. Nouzova, M.; Edwards, M.J.; Mayoral, J.G.; Noriega, F.G. A coordinated expression of biosynthetic enzymes controls the flux of juvenile hormone precursors in the corpora allata of mosquitoes. Insect Biochem. Mol. Biol. 2011, 41, 660-669. [CrossRef] [PubMed]

24. Homma, Y.; Mita, K.; Nakamura, Y.; Namiki, T.; Noda, H.; Shinoda, T.; Togawa, T. Identification of novel genes expressed highly and selectively in the corpora allata of the silkworm, Bombyx mori (Lepidoptera: Bombycidae). Appl. Entomol. Zool. 2019, 55, 45-54. [CrossRef]

25. Bellés, X.; Maestro, J.-L.; Piulachs, M.-D.; Johnsen, A.H.; Duve, H.; Thorpe, A. Allatostatic neuropeptides from the cockroach Blattella germanica (L.) (Dictyoptera, Blattellidae). Identification, immunolocalization and activity. Regul. Pept. 1994, 53, $237-247$. [CrossRef]

26. Verlinden, H.; Gijbels, M.; Lismont, E.; Lenaerts, C.; Vanden Broeck, J.; Marchal, E. The pleiotropic allatoregulatory neuropeptides and their receptors: A mini-review. J. Insect Physiol. 2015, 80, 2-14. [CrossRef] [PubMed]

27. Gruntenko, N.E.; Rauschenbach, I.Y. Interplay of JH, 20E and biogenic amines under normal and stress conditions and its effect on reproduction. J. Insect Physiol. 2008, 54, 902-908. [CrossRef]

28. Borras-Castells, F.; Nieva, C.; Maestro, J.L.; Maestro, O.; Belles, X.; Martín, D. Juvenile hormone biosynthesis in adult Blattella germanica requires nuclear receptors Seven-up and FTZ-F1. Sci. Rep. 2017, 7, e40234. [CrossRef] [PubMed]

29. Kramer, S.J.; Toschi, A.; Miller, C.A.; Kataoka, H.; Quistad, G.B.; Li, J.P.; Carney, R.L.; Schooley, D.A. Identification of an allatostatin from the tobacco hornworm Manduca sexta. Proc. Natl. Acad. Sci. USA 1991, 88, 9458. [CrossRef] [PubMed] 
30. Blackburn, M.B.; Wagner, R.M.; Kochansky, J.P.; Harrison, D.J.; Thomas-Laemont, P.; Raina, A.K. The identification of two myoinhibitory peptides, with sequence similarities to the galanins, isolated from the ventral nerve cord of Manduca sexta. Regul. Pept. 1995, 57, 213-219. [CrossRef]

31. Blackburn, M.B.; Jaffe, H.; Kochansky, J.; Raina, A.K. Identification of four additional myoinhibitory peptides (MIPs) from the ventral nerve cord of Manduca sexta. Arch. Insect Biochem. Physiol. 2001, 48, 121-128. [CrossRef] [PubMed]

32. Hoffmann, K.H.; Meyering-Vos, M.; Lorenz, M.W. Allatostatins and allatotropins: Is the regulation of corpora allata activity their primary function? Eur. J. Entomol. 1999, 96, 255-266.

33. Lorenz, M.W.; Kellner, R.; Hoffmann, K.H. A family of neuropeptides that inhibit juvenile hormone biosynthesis in the Cricket, Gryllus bimaculatus. J. Biol. Chem. 1995, 270, 21103-21108. [CrossRef] [PubMed]

34. Lorenz, M.W.; Kellner, R.; Hoffmann, K.H.; Gäde, G. Identification of multiple peptides homologous to cockroach and cricket allatostatins in the stick insect Carausius morosus. Insect Biochem. Mol. Biol. 2000, 30, 711-718. [CrossRef]

35. Lubawy, J.; Marciniak, P.; Kuczer, M.; Rosiński, G. Myotropic activity of allatostatins in tenebrionid beetles. Neuropeptides 2018, 70, 26-36. [CrossRef] [PubMed]

36. Weaver, R.J.; Audsley, N. Neuropeptides of the beetle, Tenebrio molitor identified using MALDI-TOF mass spectrometry and deduced sequences from the Tribolium castaneum genome. Peptides 2008, 29, 168-178. [CrossRef]

37. Woodhead, A.P.; Stay, B.; Seidel, S.L.; Khan, M.A.; Tobe, S.S. Primary structure of four allatostatins: Neuropeptide inhibitors of juvenile hormone synthesis. Proc. Natl. Acad. Sci. USA 1989, 86, 5997. [CrossRef] [PubMed]

38. Kataoka, H.; Toschi, A.; Li Jorge, P.; Carney Robert, L.; Schooley David, A.; Kramer Steven, J. Identification of an allatotropin from adult Manduca Sexta. Science 1989, 243, 1481-1483. [CrossRef] [PubMed]

39. Janzen, W.P.; Menold, M.; Granger, N.A. Effects of endogenous esterases and an allatostatin on the products of Manduca sexta larval corpora allata in vitro. Physiol. Entomol. 1991, 16, 283-293. [CrossRef]

40. Coast, G.M.; Schooley, D.A. Toward a consensus nomenclature for insect neuropeptides and peptide hormones. Peptides 2011, 32, 620-631. [CrossRef] [PubMed]

41. Abdel-latief, M.; Hoffmann, K.H. Neuropeptide regulators of the juvenile hormone biosynthesis (in vitro) in the beetle, Tenebrio molitor (Coleoptera, Tenebrionidae). Arch. Insect Biochem. Physiol. 2010, 74, 135-146. [CrossRef] [PubMed]

42. Abdel-latief, M.; Hoffmann, K.H. Functional activity of allatotropin and allatostatin in the pupal stage of a holometablous insect, Tribolium castaneum (Coleoptera, Tenebrionidae). Peptides 2014, 53, 172-184. [CrossRef] [PubMed]

43. Meng, Q.-W.; Liu, X.-P.; Lü, F.-G.; Fu, K.-Y.; Guo, W.-C.; Li, G.-Q. Involvement of a putative allatostatin in regulation of juvenile hormone titer and the larval development in Leptinotarsa decemlineata (Say). Gene 2015, 554, 105-113. [CrossRef] [PubMed]

44. Zamore, P.D. RNA interference: Listening to the sound of silence. Nat. Struct. Biol. 2001, 8, 746-750. [CrossRef] [PubMed]

45. Fire, A.; Xu, S.; Montgomery, M.K.; Kostas, S.A.; Driver, S.E.; Mello, C.C. Potent and specific genetic interference by doublestranded RNA in Caenorhabditis elegans. Nature 1998, 391, 806-811. [CrossRef] [PubMed]

46. Adams Mark, D.; Celniker Susan, E.; Holt Robert, A.; Evans Cheryl, A.; Gocayne Jeannine, D.; Amanatides Peter, G.; Scherer Steven, E.; Li Peter, W.; Hoskins Roger, A.; Galle Richard, F.; et al. The genome sequence of Drosophila melanogaster. Science 2000 287, 2185-2195. [CrossRef] [PubMed]

47. Baum, J.A.; Bogaert, T.; Clinton, W.; Heck, G.R.; Feldmann, P.; Ilagan, O.; Johnson, S.; Plaetinck, G.; Munyikwa, T.; Pleau, M.; et al Control of coleopteran insect pests through RNA interference. Nat. Biotechnol. 2007, 25, 1322-1326. [CrossRef] [PubMed]

48. Price, D.R.G.; Gatehouse, J.A. RNAi-mediated crop protection against insects. Trends Biotechnol. 2008, 26, 393-400. [CrossRef] [PubMed]

49. Huvenne, H.; Smagghe, G. Mechanisms of dsRNA uptake in insects and potential of RNAi for pest control: A review. J. Insect Physiol. 2010, 56, 227-235. [CrossRef] [PubMed]

50. Schlüns, H.; Crozier, R.H. Relish regulates expression of antimicrobial peptide genes in the honeybee, Apis mellifera, shown by RNA interference. Insect Mol. Biol. 2007, 16, 753-759. [CrossRef]

51. Marco Antonio, D.S.; Guidugli-Lazzarini, K.R.; do Nascimento, A.M.; Paulino Simoes, Z.L.; Hartfelder, K. RNAi-mediated silencing of vitellogenin gene function turns honeybee (Apis mellifera) workers into extremely precocious foragers. Naturwissenschaften 2008, 95, 953-961. [CrossRef]

52. Lum, L.; Yao, S.; Mozer, B.; Rovescalli, A.; Von Kessler, D.; Nirenberg, M.; Beachy, P.A. Identification of hedgehog pathway components by RNAi in Drosophila cultured cells. Science 2003, 299, 2039-2045. [CrossRef] [PubMed]

53. Dietzl, G.; Chen, D.; Schnorrer, F.; Su, K.-C.; Barinova, Y.; Fellner, M.; Gasser, B.; Kinsey, K.; Oppel, S.; Scheiblauer, S.; et al. A genome-wide transgenic RNAi library for conditional gene inactivation in Drosophila. Nature 2007, 448, 151-156. [CrossRef] [PubMed]

54. Arakane, Y.; Hogenkamp, D.G.; Zhu, Y.C.; Kramer, K.J.; Specht, C.A.; Beeman, R.W.; Kanost, M.R.; Muthukrishnan, S. Characterization of two chitin synthase genes of the red flour beetle, Tribolium castaneum, and alternate exon usage in one of the genes during development. Insect Biochem. Mol. Biol. 2004, 34, 291-304. [CrossRef] [PubMed]

55. Suzuki, Y.; Truman, J.W.; Riddiford, L.M. The role of Broad in the development of Tribolium castaneum: Implications for the evolution of the holometabolous insect pupa. Development 2008, 135, 569-577. [CrossRef]

56. Chen, X.; Tian, H.; Zou, L.; Tang, B.; Hu, J.; Zhang, W. Disruption of Spodoptera exigua larval development by silencing chitin synthase gene A with RNA interference. Bull. Entomol. Res. 2008, 98, 613-619. [CrossRef] [PubMed] 
57. Tian, H.; Peng, H.; Yao, Q.; Chen, H.; Xie, Q.; Tang, B.; Zhang, W. Developmental control of a Lepidopteran pest Spodoptera exigua by ingestion of bacteria expressing dsRNA of a non-midgut gene. PLoS ONE 2009, 4, e6225. [CrossRef] [PubMed]

58. Terenius, O.; Papanicolaou, A.; Garbutt, J.S.; Eleftherianos, I.; Huvenne, H.; Kanginakudru, S.; Albrechtsen, M.; An, C.; Aymeric, J.-L.; Barthel, A.; et al. RNA interference in Lepidoptera: An overview of successful and unsuccessful studies and implications for experimental design. J. Insect Physiol. 2011, 57, 231-245. [CrossRef] [PubMed]

59. Bhargava, A.; Clifton, M.S.; Mhsake, P.; Liao, M.; Pothoulakis, C.; Leeman, S.E.; Grady, E.F. Local injection of dsRNA targeting calcitonin receptor-like receptor (CLR) ameliorates Clostridium difficile toxin A-induced ileitis. Proc. Natl. Acad. Sci. USA 2013, 110, 731-736. [CrossRef]

60. Yu, N.; Christiaens, O.; Liu, J.; Niu, J.; Cappelle, K.; Caccia, S.; Huvenne, H.; Smagghe, G. Delivery of dsRNA for RNAi in insects: An overview and future directions. Insect Sci. 2012, 20,4-14. [CrossRef]

61. Mao, Y.-B.; Cai, W.-J.; Wang, J.-W.; Hong, G.-J.; Tao, X.-Y.; Wang, L.-J.; Huang, Y.-P.; Chen, X.-Y. Silencing a cotton bollworm P450 monooxygenase gene by plant-mediated RNAi impairs larval tolerance of gossypol. Nat. Biotechnol. 2007, 25, 1307-1313. [CrossRef] [PubMed]

62. Altschul, S.F.; Gish, W.; Miller, W.; Myers, E.W.; Lipman, D.J. Basic local alignment search tool. J. Mol. Biol. 1990, 215, 403-410. [CrossRef]

63. Gasteiger, J.; Hristozov, D. Coding and decoding chemical structure information. Abstr. Pap. Am. Chem. Soc. 2005, $229,761$.

64. Emanuelsson, O.; Nielsen, H.; Brunak, S.; von Heijne, G. Predicting subcellular localization of proteins based on their N-terminal amino acid sequence. J. Mol. Biol. 2000, 300, 1005-1016. [CrossRef]

65. Veenstra, J.A. Mono- and dibasic proteolytic cleavage sites in insect neuroendocrine peptide precursors. Arch. Insect Biochem. Physiol. 2000, 43, 49-63. [CrossRef]

66. Lubawy, J.; Marciniak, P.; Rosiński, G. Identification, localization in the central nervous system and novel myostimulatory effect of allatostatins in Tenebrio molitor beetle. Int. J. Mol. Sci. 2020, 21, 3510. [CrossRef]

67. Defelipe, L.A.; Dolghih, E.; Roitberg, A.E.; Nouzova, M.; Mayoral, J.G.; Noriega, F.G.; Turjanski, A.G. Juvenile hormone synthesis: "esterify then epoxidize" or "epoxidize then esterify"? Insights from the structural characterization of juvenile hormone acid methyltransferase. Insect Biochem. Mol. Biol. 2011, 41, 228-235. [CrossRef] [PubMed]

68. Schiesari, L.; Kyriacou, C.P.; Costa, R. The hormonal and circadian basis for insect photoperiodic timing. FEBS Lett. 2011, 585, 1450-1460. [CrossRef]

69. Nouzova, M.; Michalkova, V.; Ramirez, C.E.; Fernandez-Lima, F.; Noriega, F.G. Inhibition of juvenile hormone synthesis in mosquitoes by the methylation inhibitor 3-deazaneplanocin A (DZNep). Insect Biochem. Mol. Biol. 2019, 113, 103183. [CrossRef]

70. Ma, H.-Y.; Li, Y.-Y.; Li, L.; Tan, Y.; Pang, B.-P. Regulation of juvenile hormone on summer diapause of Geleruca daurica and its pathway analysis. Insects 2021, 12, 237. [CrossRef]

71. Liu, W.; Li, Y.; Zhu, L.; Zhu, F.; Lei, C.-L.; Wang, X.-P. Juvenile hormone facilitates the antagonism between adult reproduction and diapause through the methoprene-tolerant gene in the female Colaphellus bowringi. Insect Biochem. Mol. Biol. 2016, 74, 50-60. [CrossRef]

72. Tobe, S.S.; Stay, B. Modulation of juvenile hormone synthesis by an analogue in the cockroach. Nature 1979, 281, 481-482 [CrossRef]

73. Rüegg, R.P.; Lococo, D.J.; Tobe, S.S. Control of corpus allatum activity in Diploptera punctata: Roles of the pars intercerebralis and pars lateralis. Experientia 1983, 39, 1329-1334. [CrossRef]

74. Stay, B.; Sereg Bachmann, J.A.; Stoltzman, C.A.; Fairbairn, S.E.; Yu, C.G.; Tobe, S.S. Factors affecting allatostatin release in a cockroach (Diploptera punctata): Nerve section, juvenile hormone analog and ovary. J. Insect Physiol. 1994, 40, 365-372. [CrossRef]

75. Khan, M.A.; Koopmanschap, A.B.; de Kort, C.A.D. The effects of juvenile hormone, 20-hydroxyecdysone and precocene II on activity of corpora allata and the mode of negative-feedback regulation of these glands in the adult Colorado potato beetle. $J$. Insect Physiol. 1982, 28, 995-1001. [CrossRef]

76. Khan, M.A.; Koopmanschap, A.B.; Privee, H.; de Kort, C.A.D. The mode of regulation of the corpus allatum activity during starvation in adult females of the Colorado potato beetle, Leptinotarsa decemlineata (Say). J. Insect Physiol. 1982, 28, 791-796. [CrossRef]

77. Veenstra, J.A. Allatostatin C and its paralog allatostatin double C: The arthropod somatostatins. Insect Biochem. Mol. Biol. 2009, 39, 161-170. [CrossRef]

78. Dong, Y.-Q.; Wang, Z.-Y.; Jing, T.-Z. Functional characterization of ASTC (allatostatin C) and ASTCC (allatostatin double C) in Clostera anastomosis (Lepidoptera: Notodontidae). Gene 2017, 598, 1-8. [CrossRef]

79. Griebler, M.; Westerlund, S.A.; Hoffmann, K.H.; Meyering-Vos, M. RNA interference with the allatoregulating neuropeptide genes from the fall armyworm Spodoptera frugiperda and its effects on the JH titer in the hemolymph. J. Insect Physiol. 2008, 54, 997-1007. [CrossRef]

80. Konopova, B.; Jindra, M. Broad-Complex acts downstream of Met in juvenile hormone signaling to coordinate primitive holometabolan metamorphosis. Development 2008, 135, 559-568. [CrossRef]

81. Weaver, R.J.; Audsley, N. Neuropeptide regulators of juvenile hormone synthesis. Ann. N. Y. Acad. Sci. 2009, 1163, 316-329. [CrossRef]

82. Stay, B. A review of the role of neurosecretion in the control of juvenile hormone synthesis: A tribute to Berta Scharrer. Insect Biochem. Mol. Biol. 2000, 30, 653-662. [CrossRef] 
83. Dai, L.; Wang, C.; Zhang, X.; Yu, J.; Zhang, R.; Chen, H. Two CYP4 genes of the Chinese white pine beetle, Dendroctonus armandi (Curculionidae: Scolytinae), and their transcript levels under different development stages and treatments. Insect Mol. Biol. 2014, 23, 598-610. [CrossRef] [PubMed]

84. Zhao, M.; Dai, L.; Fu, D.; Gao, J.; Chen, H. Electrophysiological and behavioral responses of Dendroctonus armandi (Coleoptera: Curculionidae: Scolytinae) to two candidate pheromone components: Frontalin and exo-brevicomin. Chemoecology 2017, 27, 91-99. [CrossRef]

85. Le, S.Q.; Gascuel, O. An improved general amino acid replacement matrix. Mol. Biol. Evol. 2008, 25, 1307-1320. [CrossRef] [PubMed]

86. Kumar, S.; Stecher, G.; Tamura, K. MEGA7: Molecular evolutionary genetics analysis version 7.0 for bigger datasets. Mol. Biol. Evol. 2016, 33, 1870-1874. [CrossRef]

87. Huang, Z.Y.; Lin, S.; Ahn, K. Methoprene does not affect juvenile hormone titers in honey bee (Apis mellifera) workers. Insect Sci. 2016, 25, 235-240. [CrossRef]

88. Sun, Y.; Fu, D.; Kang, X.; Liu, B.; Ning, H.; Chen, H. Function of mevalonate pathway genes in the synthesis of frontalin in Chinese white pine beetle, Dendroctonus armandi (curculionidae: Scolytinae). Arch. Insect Biochem. Physiol. 2021, 107, e21828. [CrossRef]

89. Keeling, C.I.; Chiu, C.C.; Aw, T.; Li, M.; Henderson, H.; Tittiger, C.; Weng, H.B.; Blomquist, G.J.; Bohlmann, J. Frontalin pheromone biosynthesis in the mountain pine beetle, Dendroctonus ponderosae, and the role of isoprenyl diphosphate synthases. Proc. Natl. Acad. Sci. USA 2013, 110, 18838-18843. [CrossRef]

90. Dai, L.; Ma, M.; Wang, C.; Shi, Q.; Zhang, R.; Chen, H. Cytochrome P450s from the Chinese white pine beetle, Dendroctonus armandi (Curculionidae: Scolytinae): Expression profiles of different stages and responses to host allelochemicals. Insect Biochem. Mol. Biol. 2015, 65, 35-46. [CrossRef]

91. Gillespie, M.J.; Fisher, L. Confidence bands for the kaplan-meier survival curve estimate. Ann. Stat. 1979, 7, 920-924. [CrossRef] 